\title{
SELF-PROTECTION AND COPING STRATEGIES OF REFUGEES FROM SYRIA AND HOST COMMUNITIES IN LEBANON
}

\section{A study conducted by Merits Partnership in collaboration with Oxfam}

Lebanon has felt the impact of the Syrian crisis politically, socially and economically. Five years into the crisis and with an all-out war on its doorstep, Lebanon now hosts the highest number of refugees per capita in the world.

This research project aimed to improve Oxfam's understanding of the protection challenges faced by refugees from Syria as well as the protection concerns arising from the coping strategies that they use to try to meet those challenges, and the issues faced by host communities in Lebanon. The study also looks at the livelihood challenges and coping strategies that can give rise to protection issues, particularly for vulnerable refugee populations. The research results were used to contribute to the Oxfam discussion paper 'Lebanon Looking Ahead in Times of Crisis'.

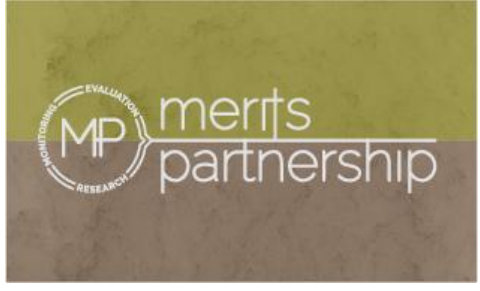


Oxfam Research Reports are written to share research results, to contribute to public debate and to invite feedback on development and humanitarian policy and practice. They do not necessarily reflect Oxfam policy positions. The views expressed are those of the authors and not necessarily those of Oxfam.

For more information, or to comment on this document, email Valentina Bacchin at vbacchin@oxfam.org.uk

\section{ACKNOWLEDGEMENTS}

Oxfam is extremely grateful to all the individuals and local authorities and civil society members who have accepted to participate in the research through interviews as well as feedback on the preliminary findings. For protection reasons, the pictures and names of the households have not been recorded or shared in the report. The active participation of Oxfam staff as well as national and international organizations with whom the initial results were discussed has helped greatly in shaping the rest of the research and this report.

Meeting interviewees was made possible by the active support of the Oxfam team in Bekaa and of partner organizations in other governorates. In particular, we would like to thank Utopia in Tripoli, Najdeh in all the Palestinian camps and gatherings targeted, and DPNA in Saida. 


\section{ACRONYMS}

$\begin{array}{ll}\text { ALEF } & \text { Act for Human Rights } \\ \text { CLA } & \text { Counseling and Legal Assistance } \\ \text { CS } & \text { Collective Shelter } \\ \text { GBV } & \text { Gender-based violence } \\ \text { GSO } & \text { General Security Office } \\ \text { HIV } & \text { Human Immunodeficiency Virus } \\ \text { ICLA } & \text { Information, Counseling and Legal Assistance } \\ \text { ID } & \text { Identity document } \\ \text { ILO } & \text { International Labor Organization } \\ \text { IS } & \text { Informal settlement } \\ \text { ISIS } & \text { Islamic State of Iraq and Syria } \\ \text { ITS } & \text { Informal tented settlement }\end{array}$

MEAL Monitoring, evaluation, accountability and learning

NFI Non-food item

OCHA Office for the Coordination of Humanitarian Affairs

PARD Popular Aid for Relief and Development

PHC Public health center

$\mathrm{PRL} \quad$ Palestine refugees in Lebanon

PRS Palestine refugees from Syria

TOR Terms of reference

UK United Kingdom

UN United Nations

UNDP United Nations Development Programme

UNHCR Office of the United Nations High Commissioner for Refugees

UNRWA United Nations Relief and Works Agency

US\$ United States dollar

WASH Water, sanitation and hygiene

WFP World Food Programme 


\section{CONTENTS}

Introduction

1 Context and Purpose of the Research ................................................ 5

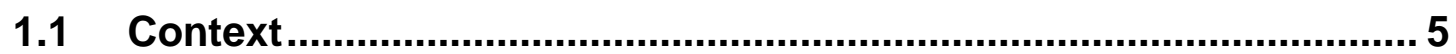

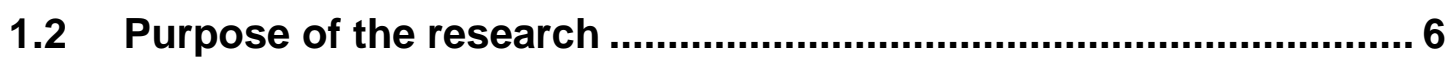

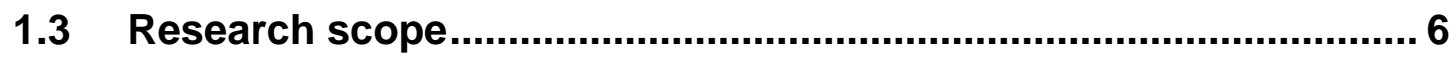

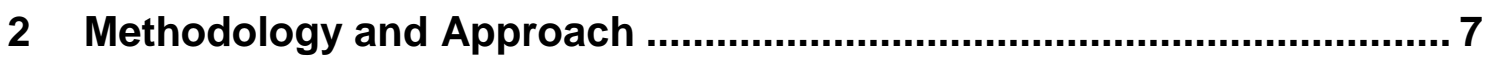

3 Research Findings: Refugees from Syria .......................................... 12

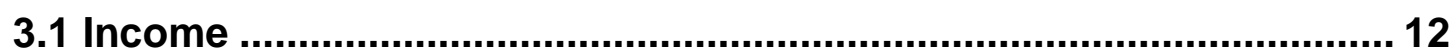

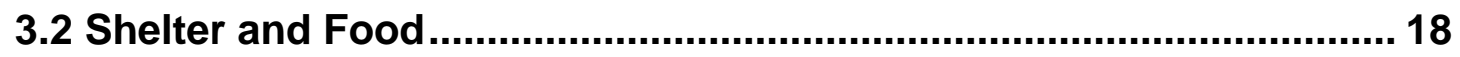

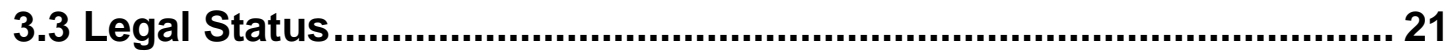

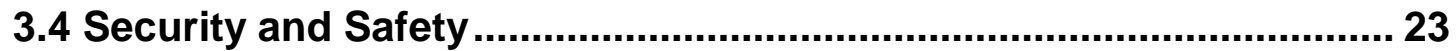

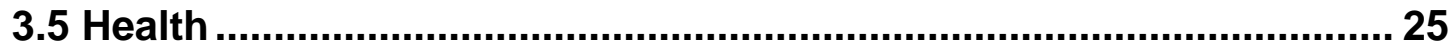

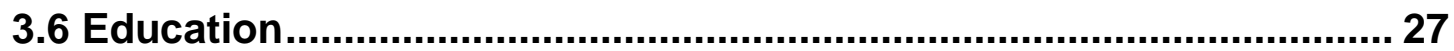

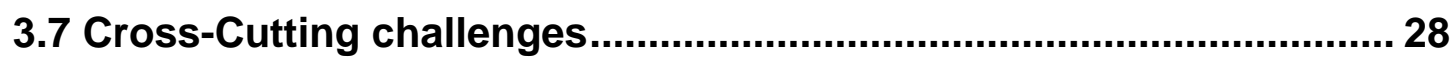

3.8 Conclusions: Refugees from Syria .................................................... 30

4 Research Findings - Host Communities in Lebanon: Competing for Scarce Resources for Already Vulnerable Populations ........................... 31

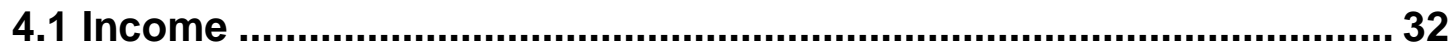

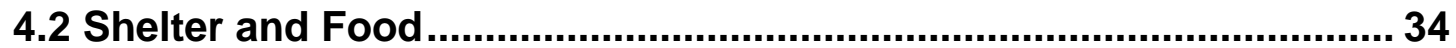

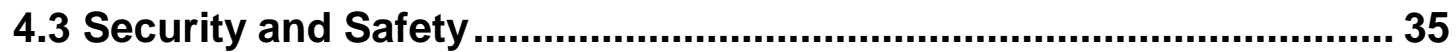

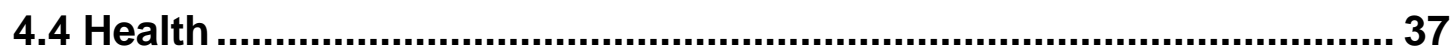

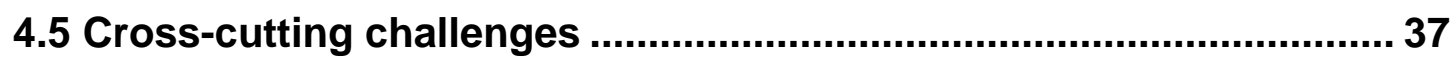

4.6 Conclusions: Host Communities in Lebanon..................................... 40

Appendix - List of Documents Consulted ................................................. 41

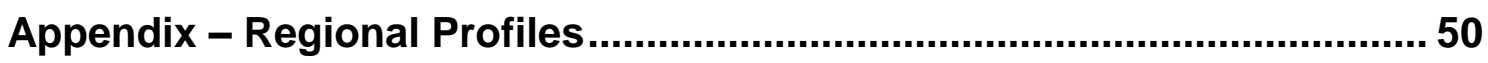

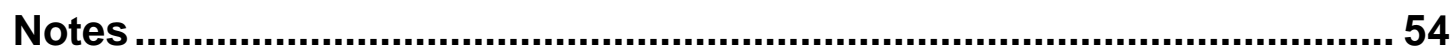




\section{INTRODUCTION}

This final report presents the research findings of the project 'Research into self-protection and coping strategies of refugees from Syria and host communities in Lebanon'.

The report is organized into six sections, as follows:

- Section 1: Introduction

- Section 2: Context and Purpose of the Research

- Section 3: Approach and Methodology

- Section 4: Research Findings - Refugees from Syria

- Section 5: Research Findings - Host Communities in Lebanon: Competing for Scarce Resources for Already Vulnerable Populations

- Section 6: Recommendations

The report also contains the following appendices:

- Appendix I: Terms of Reference

- Appendix II: Interview Protocol

- Appendix III: List of Documents Consulted

- Appendix IV: List of Other Stakeholder Interviewees

- Appendix V: Regional Profiles

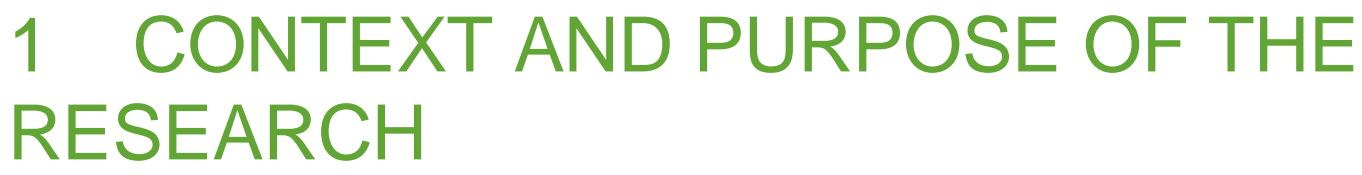

\subsection{CONTEXT ${ }^{1}$}

The ongoing crisis in Syria has led to the displacement of well over one million refugees into neighbouring Lebanon since 2011, including approximately 1.2 million Syrians who are registered with the Office of the United Nations High Commissioner for Refugees (UNHCR) and about 44,000 Palestine refugees from Syria (PRS). ${ }^{2}$ There are also hundreds of thousands of unregistered refugees. ${ }^{3}$ As of 2014 , Lebanon is the country that is hosting the second largest number of refugees in the world according to UNHCR. Moreover the number of refugees is roughly equivalent to a third of the pre-Syria crisis population of the country. ${ }^{4}$

The refugees have settled all over Lebanon, with slightly more in Beirut and Mount Lebanon (about 340,000), the Bekaa (about 415,000) and North Lebanon (about 285,000) and slightly less in the South (about 140,000). ${ }^{5}$ Many of these refugees have very difficult living situations marked by limited and precarious access to work as well as significant reliance on external livelihood sources from local and international organizations, and on borrowing money, which has given rise to '...more severe and irreversible coping strategies to meet their basic needs. ${ }^{6}$ Significant difficulties accessing adequate food, very poor quality of shelter, as well as education and health challenges are also widespread among the refugees. Furthermore, they struggle to meet the restrictive residency visa renewal rules, and face chronic safety and security concerns in their daily lives. 
The arrival of the refugees has had a significant impact on the host communities, both Lebanese and Palestine refugees in Lebanon (PRL). This impact is particularly acute for the poor and vulnerable in the host communities, who are directly affected for example, in terms of their ability to find jobs and as a result of decreasing salaries coupled with increasing prices for rental accommodation and basic necessities. Compounding the impact is the fact that many of these people were already living in very difficult circumstances before the arrival of the refugees - indeed, a 2008 study found that nearly $28 \%$ of the Lebanese population was poor and $8 \%$ were living in extreme poverty, with about 300,000 people unable to meet their most basic food and non-food needs. ${ }^{7}$

Oxfam began working in Lebanon in the 1980s, and continued its activities since then, greatly scaling up its efforts in the country in response to the outbreak of the Syria crisis. Oxfam's work in response to the Syria crisis has primarily involved activities related to water, sanitation and hygiene (WASH); the provision of cash and relief supplies; acting as an information source for refugees; and working with its various partners to try to promote an improved situation for refugees as well as a political solution to the conflict.

\subsection{PURPOSE OF THE RESEARCH}

The research project aimed to improve understanding of the protection challenges faced by refugees from Syria as well as the protection concerns arising from the coping strategies that they use to try to meet those challenges. The project also aimed to improve understanding of the protection challenges faced by host communities in Lebanon and the protection concerns arising from the coping strategies that they use in response to them. More fundamentally, it was interested in elucidating the circumstances, choices, perceptions, behaviours and motivations of refugees and host communities aimed at mastering, tolerating, reducing or minimizing their circumstances, and how these give rise to protection concerns.

While the study has a protection focus, it also recognizes that livelihood challenges and coping strategies can give rise to protection issues, particularly for vulnerable refugee populations. ${ }^{8}$ It thus also considers livelihood issues where relevant, as a means to understand the related protection concerns.

The underlying purpose of the study is to provide a reliable evidence base for Oxfam and its partners to draw on in developing suitable response programming, as well as to inform policy recommendations aimed at better supporting refugees and host communities.

\subsection{RESEARCH SCOPE}

The study's focus on refugees from Syria encompasses Syrian refugees but also PRS, the latter being a comparatively little-examined population with sometimes overlapping and sometimes distinct challenges and coping strategies. Similarly, the consideration of host communities is interested in finding out about the challenges and coping strategies of Lebanese host communities but also PRL, again because PRL have been relatively little examined as a host community and have both overlapping and distinct challenges and coping strategies. In considering the host communities, particular attention was given to Lebanese and PRL living alongside the refugees from Syria and therefore most directly affected by their presence. Similarly, the refugee populations focused upon were among the most poor and vulnerable rather than the full spectrum of people displaced from Syria and living in Lebanon.

The study was carried out in five regions of the country: the cities of Beirut and Tripoli; Bekaa (Central and North), the South (around Saida) and Akkar. It should be noted here that that the coverage of the study is not intended to be a 'national' survey in the sense of definitively 
capturing the overall situation in Lebanon, or even the overall situation in a given region. Rather, it is a series of snapshots that make it possible to highlight issues, strategies and characteristics particular to the people being studied, which can in turn inform efforts at understanding other people in similar circumstances. This issue as well as the rationale for the selection of these regions are further discussed in the Approach and Methodology section.

The understanding of protection that was drawn on in this study is based on the IASC definition of protection, and flows from Oxfam's protection framework, which is a succinct definition that reflects the core components of protection. ${ }^{9}$ The framework is based on a risk reduction model: Risk $=$ Threat + Vulnerability $x$ Time $^{10}$

\section{METHODOLOGY AND APPROACH}

The intended purpose of this study was the primary element guiding the methodological and approach decisions. The purpose of this research is to increase Oxfam's understanding of the protection challenges and coping strategies of both refugees from Syria and host communities in Lebanon. With this purpose in mind, we chose to take a primarily qualitative approach for this study.

This methodological approach was chosen as it is the most appropriate to capture protectionbased concerns and to understand decision making processes of affected populations, which quantitative approaches are not typically able to obtain through closed-answer surveys. Indeed, the fundamental principles of social science research methods recognize that 'If [the researcher] wants to understand the experiences of an individual (or a community) from a first-person perspective, a qualitative approach must be taken. ${ }^{11}$

In addition, in order to fill the remaining gaps in the knowledge and understanding of the situation and coping strategies of Syrian refugees in Lebanon, and even more so of the host communities, we decided to use open-ended, semi-structured interviews rather than closedanswer survey questions. This is especially appropriate in light of the nature of the information sought, dealing in particular with protection challenges and coping strategies of vulnerable populations. Open-ended questions allow respondents to define for themselves what their concerns and challenges are, rather than focusing on a predetermined set of issues identified by the researchers or aid agencies. Indeed, semi-structured interviews allow us to 'reach the parts which other methods cannot reach', in that interviews allow the researchers to 'probe an interviewee's thoughts, values, prejudices, perceptions, views, feelings and perspectives. We can also elicit their version or their account of situations which they may have lived or taught through: his or her story. ${ }^{, 12}$ The broad interview protocol is included in Appendix II of this report.

It should be noted that the purpose of our research is not to replace but rather to complement the existing quantitative data. Therefore, the information gathered through this study is not intended to be statistically representative. However, the researchers were mindful to ensure that the research did not amount to a series of anecdotes by applying appropriate measures to ensure the data's reliability and validity, assessing both the objectivity and the credibility of the research. Validity relates to the honesty and genuineness of the research data, while reliability relates to the reproducibility and stability of the data.

The validity of research findings refers to the extent to which the findings are an accurate representation of the phenomena they are intended to represent. Validity can be substantiated by a number of techniques including triangulation use of contradictory evidence, respondent validation, and constant comparison. Given the nature of the research, as well as the constraints of time and resources within which this study was undertaken, the researchers 
focused their verification on a modified form of respondent validation, and on constant comparison.

Respondent validation means 'allowing participants to read through the data and analyses and provide feedback on the researchers' interpretations of their responses [This] provides researchers with a method of checking for inconsistencies, challenges the researchers' assumptions, and provides them with an opportunity to re-analyse their data. ${ }^{13}$ In this case, since it would not be possible to engage directly with the respondents, we instead discussed our emerging observations and assessments regularly with Oxfam staff and other key informants. We also relied on the technique of constant comparison, where one piece of data (in this case, an interview) was compared with previous data and not considered on its own, enabling researchers to treat the data as a whole rather than fragmenting it.

The use of constant comparison was also especially useful for this study, as it enabled the researchers to identify unanticipated themes within the research project. As a result, the report is organized on the basis of the challenges articulated by the refugees who were interviewed, and the section on host communities presents challenges in the same order for the sake of easier comparability. The major themes that emerged from our interviews are: income, shelter and food, legal status, security and safety, health, education, and several cross-cutting challenges. In general, refugees brought up the challenges of income, shelter and food, and legal status first, more frequently and spoke about them in more detail, with the other challenges mentioned by more specific respondent groups. The host community members also spoke about income as well as shelter and food, then tended to emphasise security and safety, as well as health.

In the interest of ensuring that our data would not be anecdotal, we sought to maximize the number of interviewees spoken with for each category and in each region. For that reason, we tried whenever possible to conduct group rather than individual interviews. There is always a concern with group interviews - especially when dealing with potentially sensitive topics - that individual experiences will not be captured. However, again informed by the principles of social science research, we believe that, in group settings: 'the interviewees may feel safer, more secure and at ease if they are with their peers (...). They are also more likely to relax, "warm up" and jog each other's memories and thoughts. ${ }^{14}$ During the pilot phase of the study, we conducted both individual and group interviews, in order to ascertain that these principles were applicable in the specific context of this research. We were able to confirm that group interviews generally tended to generate detailed information from respondents, and that the themes raised by respondents did not vary between the two contexts.

The selection of specific interviewees was undertaken through the use of snowball methodology, beginning with existing contacts from Oxfam and/or its partners. It should be mentioned that we chose to focus on people who are among the poorest and most vulnerable of refugees, since this category is the main target for programming by Oxfam and its partners. We recognize, however, that they are not representative of all refugees from Syria in Lebanon, especially given that the refugees are a heterogeneous group. This also applies to our approach to selecting host communities for investigation, in so far as we are primarily interested in the communities that host the particular types of refugees that are the focus of this study. However, we also sought out some host community key informants, such as religious leaders, doctors and municipal authorities, who are not in this socio-economic tranche, but who can provide information on the impact on the local community as a whole of the presence of refugees.

In addition, in more general terms, we designed a purposive sample of respondents that would reflect the variables of interest to Oxfam GB's Lebanon programme, namely:

Type of respondent:

- Refugees from Syria

- Palestine Refugees from Syria (PRS) 
- Lebanese

- Palestine Refugees from Lebanon (PRL)

Age:

- 30-years-old and under

- Over 30-years-old

Gender:

- Men

- Women

Region:

- Beirut

- Tripoli

- Bekaa (primarily North Bekaa)

- the South (around Saida)

- the North (Akkar)

The selection of these categories was informed in part by the priorities of Oxfam GB's Lebanon programme, but more fundamentally they are intended to capture the experiences of both the refugees and their host communities. A key concern was to recognize that Syrian refugees and PRS face somewhat different circumstances on a variety of fronts, and that PRL represent, in this context, a different type of host community from the Lebanese population.

The disaggregation by age and gender allows us to examine whether these differences lead to a differential experience, which might identify different programming needs according to categories that do tend to impact on how people experience different situations and which carry different types of potential vulnerabilities. We chose 30 years of age as the cut-off point for the age category because this is a commonly used category to differentiate between young adults and older adults. Young adults are usually defined as being people between 18 and 30 or 18 and 34, depending on the average age of the population in a given location. Further, in the case of Lebanon, the median age is $29.3,{ }^{15}$ meaning that half the population is younger than 29.3 , and half is older. Thus, 30-years-of-age seems an appropriate cut-off point.

Further, the differentiation between young and older adults is based on the commonly observed fact that young adults tend to have different life circumstances from older adults. Indeed, they are more likely to be single and, if not, they will tend to have young children living at home. Older adults are more frequently married and are more likely to have adult children of their own. These differences in life circumstances led us to hypothesise that the challenges and coping strategies would vary significantly between these two groups. Finally, disaggregating by gender is a standard methodological tool to ensure that this dimension is taken into account when making programming decisions, as part of a gender equality perspective.

The regional selection was informed by an interest in being able to compare between regions, based on the recognition that there could be important differences between the experiences of the refugee populations and the host communities in different parts of the country. The specific regions were chosen because they are areas where Oxfam already works, whether directly or through local partners, or where it is potentially interested in working. The logic in the selection of the regions also allows the study to represent different characteristics: urban vs rural, large cities vs small towns. The broad geographic coverage of the study also allows us to make sure that the data we capture is not an anomaly resulting from the particular characteristics of the specific location, and moreover ensures that the range of refugee experiences is as fully incorporated into the study as possible, given that the purpose of the study, as was already 
mentioned, is to uncover the particularities of experiences to complement the existing quantitative information.

The inclusion in this study of this variety of regions allowed us to conduct a comparative analysis. Thus, particular characteristics of different regions - for example the security situation, the proximity to Syria, the socio-economic circumstances - are highlighted where relevant in our analysis; whereas the majority of the discussion is centred on trends observable across regions. However, it is important to reiterate that this does not make for a national-level study that can be directly generalized, either to all of Lebanon or to the entirety of the regions in which the study is conducted.

There was also an interest in the effects of the legal status of refugees on their protection challenges and coping strategies. Since the vulnerability attached to different legal situations would make it difficult to pre-select respondents on this basis, we instead attempted to obtain information regarding the legal status of respondents during interviews and take that into consideration in our analysis.

Overall, the research was composed of a combination of document review and a series of interviews. The interview component of the study was conducted between 25 February and 23 May 2015. All interviews with refugees and host communities were conducted with the aid of native-speaker interpreters familiar with the locality, to ensure that the particular dialects of Arabic were adequately understood. Table 1 below presents a breakdown of the refugee and host community interviews conducted:

\section{Table 1: Summary of interviews conducted}

\begin{tabular}{|c|c|c|c|c|c|}
\hline \multicolumn{6}{|c|}{ Region: Beirut } \\
\hline Category of respondent & Male over 30 & Male 30 and under & Female over 30 & Female 30 and under & Total \\
\hline Syrian Refugees & 3 & 2 & 2 & 1 & 8 \\
\hline PRS & 4 & 1 & 2 & 2 & 9 \\
\hline Lebanese host communities & 2 & 6 & 3 & 0 & 11 \\
\hline PRL host communities & 1 & 1 & 5 & 2 & 9 \\
\hline Totals & 10 & 10 & 12 & 5 & 37 \\
\hline \multicolumn{6}{|c|}{ Region: Tripoli (including Nahr al Bared) } \\
\hline Category of respondent & Male over 30 & Male 30 and under & Female over 30 & Female 30 and under & Total \\
\hline Syrian Refugees & 5 & 4 & 3 & 4 & 16 \\
\hline PRS & 2 & 3 & 2 & 4 & 11 \\
\hline Lebanese host communities & 4 & 1 & 1 & 2 & 8 \\
\hline PRL host communities & 1 & 1 & 1 & 2 & 5 \\
\hline Totals & 12 & 9 & 7 & 12 & 40 \\
\hline \multicolumn{6}{|c|}{ Region: Bekaa } \\
\hline Category of respondent & Male over 30 & Male $\mathbf{3 0}$ and under & Female over 30 & Female 30 and under & Total \\
\hline Syrian Refugees & 5 & 3 & 5 & 5 & 18 \\
\hline PRS & 2 & 1 & 1 & 3 & 7 \\
\hline Lebanese host communities & 7 & 1 & 2 & 2 & 12 \\
\hline PRL host communities & 2 & 2 & 6 & 1 & 11 \\
\hline Totals & 16 & 7 & 14 & 11 & 48 \\
\hline \multicolumn{6}{|c|}{ Region: South } \\
\hline Category of respondent & Male over 30 & Male 30 and under & Female over 30 & Female 30 and under & Total \\
\hline Syrian Refugees & 3 & 2 & 1 & 3 & 9 \\
\hline PRS & 6 & 2 & 7 & 3 & 18 \\
\hline Lebanese host communities & 2 & 4 & 4 & 1 & 11 \\
\hline PRL host communities & 2 & 6 & 1 & 1 & 10 \\
\hline Totals & 13 & 14 & 13 & 8 & 48 \\
\hline \multicolumn{6}{|c|}{ Region: North (Akkar) } \\
\hline Category of respondent & Male over 30 & Male 30 and under & Female over 30 & Female 30 and under & Total \\
\hline Syrian Refugees & 5 & 4 & 4 & 8 & 21 \\
\hline $\mathrm{PRS}^{*}$ & 0 & 0 & 0 & 0 & 0 \\
\hline Lebanese host communities & 9 & 1 & 3 & 2 & 15 \\
\hline PRL host communities * & 0 & 0 & 0 & 0 & 0 \\
\hline $\begin{array}{c}\text { Totals } \\
\end{array}$ & 14 & 5 & 7 & 10 & 36 \\
\hline Overall Totals & 65 & 45 & 53 & 46 & 209 \\
\hline
\end{tabular}

* The populations of PRS and PRL are negligible in the Akkar region, hence they were not targeted in this study 
In addition to interviews with refugees and host community members, we conducted a series of interviews with other stakeholders, specifically with Oxfam staff in Lebanon, UK and the region, as well as with representatives of various INGOs and NGOs, and UN agencies working in Lebanon. The purpose of these interviews was to better understand the existing knowledge gaps as well as the context of the Syrian crisis and of the Lebanese context. In addition, discussions with experts provided additional information regarding the background framework as well as technical expertise on particular topics to enhance our analysis.

The interviews were supplemented by extensive document review, particularly of Oxfam's programming and operational priorities and principles, documents provided by UN agencies, INGOs and NGOs working with refugees from Syria in Lebanon, as well as grey literature on topics ranging from similar studies conducted in other regions of the world, to publicly available results and analysis from studies on the situation of refugees from Syria in Lebanon and in the Middle East (a full list of the documents consulted is included in the appendix).

Our analytical framework consisted in aggregating thematically the information elicited through the interviews according to the main livelihoods and protection challenges raised by our interviewees, and seeking to place it in the context of Lebanon, and aiming in particular to identify actual and potential protection issues, in keeping with the overarching purpose of the research. 


\section{RESEARCH FINDINGS: REFUGEES FROM SYRIA}

In section 2, Methodology and Approach, it was noted that the organizing logic for presenting the research findings was based on the challenges articulated by the refugees. In this section, we focus on seven major themes: income, shelter and food, legal status, security and safety, health, education, and cross-cutting challenges. Differences between particular respondent groups - Syrian or PRS, male or female, 30 and under or over 30, and particular geographical regions - are highlighted whenever relevant. If not highlighted, there was no discernible difference on the issue under discussion. At the end of the section, we present some overall conclusions in regard to the refugees.

\subsection{INCOME}

As outlined in the Methodology and Approach section of this report, Oxfam's protection framework considers deliberate deprivation (including 'preventing access to land and jobs [and] deliberate discrimination in getting jobs') as a protection threat, and sees poverty as a crucial factor in increasing people's vulnerability. In that context, the livelihoods challenges faced by refugees from Syria in Lebanon and the generalized poverty they experience present clear protection concerns. They have led to a variety of coping strategies, both positive and negative, and the latter represent a real concern in terms of protection.

In general, the study finds six types of coping strategies to address lack of income:

- Spending savings and liquidating assets

- Finding work

- Resorting to aid

- Borrowing money

- Sharing resources

- Receiving remittances

\subsubsection{Spending Savings and Liquidating Assets}

The vast majority of interviewees indicated that they relied primarily on their savings on arrival in Lebanon, during the period when they were seeking a place in which to settle and therefore had not secured work or long-term shelter. The exception to this was the minority of refugees who had to leave Syria very suddenly and were thus unable to bring any savings with them, and refugees who moved around multiple times in Syria before coming to Lebanon (and hence depleted their savings before arriving).

Within a year of arrival, even those refugees who arrived with savings had typically depleted them, and liquidating assets was usually not an option, as they tend to have very few possessions. The necessity of depleting savings and assets represents a negative coping strategy. Some interviewees indicated that when they have any valuables, such as gold jewellery, liquidating them is a strategy of last resort, either because they have strong sentimental value (as is the case with wedding rings and some family heirlooms, which are emotional links to their home and/or family), or as a provision for potential future difficulties. 


\subsubsection{Finding Work}

All of the male refugees with whom we spoke are working (though in insecure employment, as will be discussed below) or seeking work more or less actively. ${ }^{16} \mathrm{~A}$ lower proportion of the female refugees are also working outside the home. Female employment is an issue that we will discuss below.

Those refugees who find work do so through a variety of strategies: through familial or other networks, by knocking on doors asking for work in farms, shops or other places of employment, and by waiting in the early morning in areas of the downtown where employers looking for day labourers will go and pick people (the latter particularly in the case of Syrians refugees in urban centres). Generally, refugees tend to find precarious, day labour positions as farmhands, shop assistants or other forms of manual labour. They are disproportionately concentrated in the construction sector (as bricklayers, masons, tilers and general labourers), especially because this is an industry where Syrians have historically worked in Lebanon as seasonal workers, even prior to the onset of the crisis in Syria.

\section{Box 1}

'Mohammed' (not his real name) is a Syrian man over 30 living in the Tabbaneh area of Tripoli. He came to Lebanon one-and-a-half years ago from a village near Aleppo with his wife and 4 children aged 5 to 11 , leaving after the street next to his was shelled by tanks and bombed by airplanes for an extended period. He used to work as a real estate agent in Syria, and owned a car and a house; now he works about one day out of nine pushing a vegetable cart in Tripoli's souq:

'I fled the war without anything. I came here and I can't make a living, people sometimes give me things but I can't pay rent and I can't pay for things. I'm afraid to walk in the streets, I start trembling because my residency permit has expired...they have put impossible conditions on us...we're suffocating, we're desperate.'

Mohammed says that there used to be more work in the souq, but now people send their boys to do the work and they'll work for less money, so employers prefer to hire them. $\mathrm{He}$ describes always being broke, and says he never pays his landlord on time and is going deeper into debt - therefore he feels that his housing situation is highly insecure. He also has injured his back at work - but when he went to the Public Health Center (PHC), they just gave him painkillers and told him to change jobs. Overall, he feels very stressed, and is always fighting with his wife and children.

Work can be a positive coping strategy, in that it can allow them to earn an income. However, our respondents are typically working for very low wages, almost always lower than those of their Lebanese counterparts. The fact that they are day labourers also means that they have little to no job security, which leaves them open to both abuse and exploitation. Indeed, most respondents noted that abuse from their employers is widespread, ranging from verbal abuse (shouting, insulting, using ethnic slurs), to arbitrarily withholding pay, threatening to fire or not hire them anymore, and threatening to report them to the authorities. This is exacerbated by the fact that employers are well aware that most refugees have expired or no residency documents, and are therefore not in a position to seek the assistance of the authorities.

In general, younger men (30-years-old and under, according to our age disaggregation of the sample) are significantly more able to obtain work than their older counterparts. For men over 40 , finding work is almost impossible, which places an additional burden on those members of 
the family who can get jobs. An added burden on some young Syrian men is that they are expected to send money back to family in Syria, to help support them. ${ }^{17}$

Women tend not to work for money if the family can obtain sufficient resources from work and/or aid, and they look after the children. When adult men cannot generate sufficient income, families consider getting younger children to work (typically teenagers but in extreme cases some as young as ten-years-old - for example, one interviewee in Akkar described 10 to 12year-old Syrians working bagging groceries in the supermarkets of his town). This has clear protection concerns, in that refugee families in those situations feel forced to rely on child labour, which clearly violates Article 32 of the Convention on the Rights of the Child. ${ }^{18}$

When family income is insufficient, women will also seek remunerated work. This is particularly the case in rural areas such as in Akkar and the Bekaa, and less frequently when the employment situation is slightly more protected, as in the case of an interviewee who ran a small store out of the front of the family's ground floor flat in Akkar along with her husband. While women working may not be intrinsically problematic, female and male interviewees from the families involved whether in rural or urban settings tended to characterize it as evidence of how bad their situation was. A further concern that was expressed by the interviewees was the safety of women working. Indeed, the precarious work in which most refugees engage exposes the women to harassment, verbal abuse, and sexual harassment and abuse. Some women, particularly those who work in shops, also indicate that they have been subjected to actual or attempted sexual blackmail, an issue to which we will return in the section on Security and Safety.

\section{Box 2}

'Fatima' (not her real name) is a Syrian woman over 30 years of age who came to the Saida area about two-and-a-half years ago from Harissa near Damascus after having moved around multiple times to towns near Damascus to escape the fighting. She came with her three children, now aged 4 to 13 , as well as her husband. When they first arrived, they stayed with her sister in a two room building in a field, then eventually moved into the sand floored stable next door because she and her husband - who had a kidney transplant shortly before they came to Lebanon, and who is still very sick - found it difficult to live in the overcrowded place. Her husband is not able to work, so for the last two years the family has been supported by her son who works at a carpet store. She says that she, her husband and her son all talked and agreed together about him getting work as they were so desperate for money to supplement the aid from the WFP. She says that it makes her very nervous when her son is walking to and from work through their unsafe neighbourhood, as she worries that he might be harassed or otherwise victimized because he is still just a child.

In general terms, refugees living in Informal Tented Settlements (ITS) in rural parts of the Bekaa and Akkar tend to have more young children (including as young as ten-years-old) and women working than those in urban areas. In all regions examined in the study, families where the male head of household is older and thus has more difficulties finding work have a greater tendency to have adult or even young children and women as the primary earners. In most cases, it will be the male children who go to work; girls will only be asked to do so as a last resort, usually only in rural settings, and rarely as young as male children.

In rural settings, women who work tend to work as farmhands. Generally, there appears to be less stigma attached to working women in those settings, likely because farming work is traditionally a family undertaking, where even in normal situations (i.e., non-crisis), all members of the household, including women and children, are expected to participate in farm work. This, however, does not apply for refugees in rural settings who were not involved in agriculture prior to the crisis. Important to note as well is that some of the women refugees did work prior to the 
crisis in Syria, most often in agricultural work though in few cases in office-type jobs. A finding particular to the refugees living in ITS in the Bekaa is that families prefer for women to work rather than men, because there is at least a perception that it is safer for them to leave the ITS than for men. As will be discussed in the section on Security and Safety, men feel they are more vulnerable to arrest, deportation and/or harassment than women.

Female-headed households typically rely more on aid, sharing resources, co-living with extended family and in multi-generational households. Children, including younger children and both daughters as well as sons, are also more likely to be working. Respondents characterized this as proof of how dire their circumstances are rather than as a positive solution. A few of our respondents indicated that some women have resorted to survival sex as a source of income, which carries well-known risks of violence and exploitation.

\section{Box 3}

'Hassan' (not his real name) is a PRS man under 30 years-of-age from Yarmouk in Syria. He lives in Nahr al-Bared camp, in some structures put up by the United Nations. Since arriving in Lebanon he has worked though only very infrequently, as a construction worker in the new part of the camp. He has also not been paid for his work on multiple occasions, with his employer saying 'next week, next week' then never paying him or only giving a small part of the money. He says that he has been involved in problems in the street in the camp, with harassment from PRLs for being 'Syrian' and for 'taking our jobs' sometimes turning into fights. He very rarely leaves the camp because his visa has expired and he is worried that he might be detained or deported.

The ability to access work is more precarious for refugees living in rural areas and especially in ITS, because both construction and agricultural work - their main sources of employment - are seasonal and unavailable during the winter. Those families therefore have to live off their savings for part of the year, but the low wages they receive makes it impossible for them to save enough money to maintain even their very low standards of living, which greatly increases their vulnerability. In general terms, while all refugees express the desire to work, PRS tend not to be in work as frequently as Syrian refugees. Indeed, according to the International Labour Organization (ILO), the unemployment rate for PRS is around $90 \%$, compared with around $50 \%$ for Syrian refugees (though this figure is higher among women). ${ }^{19}$ This is in part because they were eligible for more aid, but primarily because they tend to live in host community contexts in which there are already few opportunities for employment and because they lack the informal social networks related to employment enjoyed by Syrian refugees. Further, what little employment there is in the host community contexts where PRS tend to live - primarily in PRL communities - tends to be given preferentially to PRL. This situation is worrisome especially in light of the decision by the United Nations Relief and Works Agency (UNRWA) in June 2015 to suspend its cash-for-rent assistance to PRS. ${ }^{20}$ This is likely to lead to a major crisis for this group, since their access to work is so limited, especially within the PRL communities. In addition, they have real difficulties leaving PRL camps such as Nahr al-Bared and Ayn alHelwehh to seek work elsewhere, because they generally have no legal right to be in Lebanon (as will be discussed further in the section on Legal Status). For PRS living in the southern suburbs of Beirut, the situation may be slightly less dire, in so far as the camp boundaries are more porous and thus allow more access to employment in the surrounding neighbourhoods and moreover many PRS are living within those surrounding neighbourhoods. 


\subsubsection{Aid}

Given their generalized poverty, the difficulties in obtaining regular, secure employment that generates a sufficient income to provide for themselves and their families, and in light of the restrictions on work for those who can obtain visas (as will be discussed in the section on Legal Status), all of our interviewees seek to access aid in some form, from international organizations, INGOs, NGOs or private benefactors.

The most widespread source of aid for Syrian refugees is a conditional cash transfer provided by the World Food Programme, which can only be used to purchase food in particular stores. This is accessible through registration with UNHCR. The value of the transfer used to be US $\$ 30$ per person per month, but was reduced to US\$19 in early 2015 . This reduction was experienced as especially difficult by our respondents, and indeed was remarked on by many of them as significantly impacting on their ability to support themselves. Not only was the amount reduced, but also the eligibility criteria were restricted such that certain individuals who had been eligible no longer were. In all cases, this reduction in aid has caused indignation as well as greater hardship, as it is seen as arbitrary. Moreover since the time that the research study's interviews were carried out, the amount given was reduced again to $\$ 13.50$; which can be expected to magnify the impact on refugees still further.

PRS are usually eligible for UNRWA support, which at the time of our interviews took the form of cash transfers for rent and food (the latter using money from the World Food Programme), as well as subsidized health and education services. The majority of our PRS respondents have depended on this aid to a very large extent since, as described in the preceding section, their options for finding work are more restricted. As such, the cuts to UNRWA support and the potential for even more cuts will likely have a very significant impact on their access to income.

In addition to the support provided by the two main agencies mandated to assist refugees (UNHCR and UNRWA), many refugees from Syria may have access to aid provided by a variety of INGOs and NGOs in the form of cash and/or non-food items. Generally, this aid is provided either directly to particular individuals or families, or indirectly in the form of services provided to the community, such as WASH services or infrastructure, dedicated schools in rural areas, etc.

The individual-directed assistance has been experienced by most respondents as unfair or arbitrary, especially by those who do not receive it, either because the eligibility criteria are not always clear to them or the judgments of particular circumstances based on those criteria are perceived as unbalanced. This is especially the case for the support provided by a few private philanthropists such as sheikhs and well-off businessmen, as well as organizations with religious affiliations, both Lebanese and from other countries in the Middle East and beyond.

All respondents agree that it is not possible for them to live on aid alone, and even for those who are able to find some paid work, it is insufficient to provide for their families' needs. In addition, some respondents felt that the restrictions on the way the aid is provided, especially the World Food Programme (WFP) food assistance, make it difficult to fully benefit from even that meagre support. In particular, respondents indicated that the shops where they can use the funds tend to have higher prices than others, which means, for them, that they have to reduce the quality and quantity of their purchases. Furthermore, the types of products they are entitled to purchase mean that, if they have no other income, or their other income is insufficient, they are not able to obtain non-food goods that they deem equally necessary.

The coping strategy for bridging the cash gap adopted by most refugees from Syria is to sell NFIs in order to purchase more food or food from different (usually less expensive) suppliers. They will also sell their food vouchers to other refugees or even to third party resellers for cash to buy other types of goods, at a discount averaging approximately $25 \%$ of their value. This coping strategy can have negative implications in so far as they are deprived (even though to some extent voluntarily) from income to which they are technically entitled. 
In general terms, the availability of aid to refugees can be considered a positive income generating strategy. However, it is associated with a number of protection challenges, in so far as they need to travel to obtain both registration and the aid associated with it, and as will be discussed in the section on Security and Safety below, whereby having to pass through checkpoints poses important risks, especially for the majority who do not have valid visas or permits to be in Lebanon.

The identity-based criteria for aid eligibility (UNHCR registration for Syrian refugees and UNRWA registration for PRS) can have both positive and negative implications. On the one hand, mixed families can sometimes access assistance from both agencies (though this is often noted and resented by other refugees who cannot do so). On the other hand, the criteria can mean that a few mixed families are shut out of both aid streams, as a result of intermarriage between communities of identity as well as due to cross-border familial ties. To take an example, one female PRS interviewee is married to a Syrian and helps to support her mother who was PRL until she married a PRS man and therefore renounced her PRL status and became PRS. However, when the man left the mother several years ago, she lost her status as a PRS but has been unable to regain her PRL status. The result then is that different members of the same family have differential access to assistance as a result of sometimes complex familial ties.

\subsubsection{Borrowing}

All respondents indicate that they are forced to resort to borrowing money from family members, either in Lebanon or abroad, acquaintances or neighbours when possible. They also buy on credit from shop owners, or seek cash advances from employers. They tend to use these strategies to cover their most pressing needs, most often paying for overdue rent, or settling their account with shop owners. Our study finds no clear patterns of different use of these strategies either among the different types of respondents, nor across the different regions.

Borrowing money or purchasing goods on credit is not an unusual coping strategy to address insufficient income. However, it can have important negative implications, especially due to the informal and therefore unregulated nature of the transactions. Indeed, it exposes the borrower to abuse and exploitation, through the imposition of usurious repayment conditions, demands for unpaid labour and/or sexual exploitation. It also increases the refugees' vulnerability to threats of being reported to the authorities for those without legal permits to be in Lebanon.

\subsubsection{Sharing}

Almost all refugees interviewed also indicate that they share food and NFIs with extended family and fellow refugees on a regular basis. For particularly acute problems, they also sometimes share any available money, for instance to pay for urgent medical interventions.

The practice of sharing resources demonstrates a sense of community solidarity and can be termed a positive coping strategy, in so far as it substitutes for or recreates the social networks that were so often lost in the process of displacement, and can provide the refugees with a sense of belonging and reduce the feeling of abandonment many of them express.

\subsubsection{Remittances}

A lucky few have family or friends abroad who are in a position to provide them with additional money, either regularly or as one-off gifts. These tend to be husbands or sons, occasionally daughters, who were already working in Europe or North America, although sometimes these individuals were able to migrate there after the onset of the crisis. In one case, a family member 
living in Germany organized a collection among their neighbours to be able to send a more substantial amount of money.

This can be seen as a positive coping strategy, as it allows the refugees to increase their somewhat autonomous response to their situation without incurring additional risk of exploitation. However, it is not available to the majority of refugees.

\subsection{SHELTER AND FOOD}

Obtaining shelter and food is another basic necessity for the refugees, and is not unrelated to the need for income. Most of the refugees we interviewed choose the area where they will settle because they know it from having worked there prior to the crisis, or because they know someone (family or friends) who live there. This was true for refugees in all geographic regions of the study. In some cases, especially in rural areas, the driver of the vehicle who takes them from the border points them to particular landlords or villages/towns where they know other refugees from their area in Syria have settled. This seems to somewhat invalidate the commonly expressed assumption among some analysts that refugees will prioritize settling in areas with which they have a religious affiliation. While the use of family and social networks may have the net result of people settling in areas where the majority of people share their religious affiliation, this appear to be a by-product of the use of these personal networks, rather than an explicit deciding factor.

For our respondents, adapting their shelter situation is in fact one of the first coping strategies to address their lack of income. The first cost reduction they resort to is reducing the cost of their shelter. They tend to seek less expensive accommodation, especially in urban settings where there is a wider choice available. That said, respondents in rural parts of the Bekaa and Akkar also described moving from one ITS to another because the new ITS was less expensive.

\section{Box 4}

'Qassim' (not his real name) is a Syrian male under 30 years-of-age who lives in an ITS in the Bekaa valley, where he pays the landlord about 100 Lebanese pounds a month for rent. He has three children and his wife is pregnant with a fourth. He barely worked at all over the winter, and one of his greatest challenges is getting enough food for his family. To try to get money, he has sold non-food items that have been given to him by an aid organization, and also traded some hygiene vouchers given to him by Oxfam with another refugee so that he could buy food - but he lost a lot of the value in doing so. He is also very worried about being forced to leave ever since his landlord started threatening him with eviction and he had to beg and grovel to be able to stay. Another major concern is security. He says that things are becoming harder and harder overall - but he's not thinking about the next six months, only tomorrow.

Regarding urban settings, higher floors in buildings are in general more expensive. Thus refugees will move to the lower floors, which are cheaper because they have less ventilation and light. They also move to smaller units, with fewer rooms. In keeping with the sharing strategy described in section 4.1.5, they will often share accommodation with extended family, or sometimes with friends or neighbours. This results in multi-family households, where each family occupies a room or even a portion of the room demarcated by hanging sheets or blankets. In extreme cases, the households are so crowded that people sleep in two or three eight-hour shifts in a single room covered in mattresses, with no space for communal activities, and those who are not sleeping have to vacate the premises. 
In urban areas, they will move to neighbourhoods that have lower rental costs, even at the risk of endangering their security, such as those where there are regular armed conflagrations. This can be a short-term strategy, since rents rise as soon as the security situation improves in the neighbourhood and they may be forced to move again. For example, one woman in Tabbaneh in Tripoli said that her rent had been low because it was in a particularly dangerous area for snipers; but once the Lebanese army moved in in late 2014 and the security situation improved, her landlord sought to raise the rent which he claimed had been artificially low because of the danger.

In both urban and semi-rural contexts, families who can will sometimes rent storefronts. This allows them to combine shelter with the opportunity to set up shops. In those cases, the family lives at the back, with a sheet or tarpaulin separating the living area from the store itself.

In other cases, especially in rural areas, they move into marginal housing - chicken coops, farm sheds or barns, for which they can pay lower rent. However, this is at the cost of increased risk of exposure to the elements and reduced hygiene standards, which can have a negative effect on the families' health.

The way in which the refugees experience their shelter situation often illustrates the effect of relative deprivation. All respondents perceive their living conditions as unbearable, even though there is considerable variation in the quality of the shelter they occupy. While none of our respondents can be said to live in luxurious surroundings, and indeed all live in modest conditions at best, their experience is mediated by the comparative loss of comfort and/or hygiene and/or safety relative to their living conditions prior to the crisis in Syria.

Refugees living in rural contexts are more often living in informal tented settlements. This results in increased exposure to the elements, especially to the cold in winter, increased isolation and lack of access to services and infrastructure. Conversely, refugees living in urban contexts generally experience urban poverty, severe overcrowding, insufficient infrastructure (poor or absent sewer lines, lack of clean drinking water), and live in poorly ventilated units. ${ }^{21}$

Unsurprisingly, the conditions of the refugees from Syria lead to domestic tensions and potentially to domestic violence, generally aimed at women and children. This issue is discussed in detail in section 4.4.

PRS overwhelmingly live in PRL camps, in part because those areas are cheaper then Lebanese neighbourhoods, and in part because they may have family or friendship connections there. It must be noted that, especially in the Beirut area, the Palestinian neighbourhoods are among the poorest in the city, so they represent the cheapest accommodation options.

In a few cases, families cope with their lack of income and their inability to pay higher urban rents by having one family member, usually a husband or son, live in the city, where there are comparatively more employment opportunities, while the rest of the family moves to a different, cheaper part of the country. For example, a family in Tabanneh has a son who works and lives at a gym in Beirut, and therefore can send the family most of his pay to cover their rent and other needs. In another case, a family in Akkar is supported by a son who lives and works in Tripoli and, again, does not pay rent because he lives at his place of work.

The difficulties encountered in paying for rent by the vast majority of respondents raise important protection concerns. Their vulnerability increases because their living conditions have a negative effect on their health. More immediately, they are also placed at more direct threats of violence because they live in less secure areas, but also because they are sometimes threatened by their landlords when they cannot pay their rent in full and/or on time. Multiple 
women respondents, especially those under 30 years-of-age, indicated that they have been asked to provide sexual favours to cover unpaid rent.

Because they are often unable to pay the rent as agreed, refugees sometimes experience verbal abuse or threats of eviction. This is particularly prevalent because practically no one has a written lease to protect their tenants' rights. It must be noted that we have found no evidence of generalized or even frequent individual evictions. However, most respondents are aware that this may happen to them because they are so often late or short in their payments. Many have been threatened with eviction by their landlords, and they personally know people who have been evicted from their building. One respondent indicated that his landlord was evicting him, but his Lebanese neighbours had intervened to avert the eviction, in order to spare him what they saw as the final humiliation for an already vulnerable person.

One of the key coping strategies used by our interviewees to address housing needs and to reduce vulnerability is managing their relationship with the landlords. A very few seem to be instrumentally defaulting on their rent as a coping strategy to deal with insufficient income. They stay in one location without paying rent and move to a different one, often in the same neighbourhood or area, when their lack of payment causes them to be evicted. Others respond by making sure the first payment they make when they receive aid of any kind is to their landlord. In fact, landlords are very aware of the dates when aid is received and they often insist on getting paid on those days. In some cases, this means that cash received for particular purposes, such as winterization of dwellings, is instead spent on paying the rent.

Some landlords, particularly though not exclusively in rural areas, will allow the refugees to pay their rent through labour. While this can sometimes free up cash income for other purposes, it also sometimes leads to exploitation, as landlords occasionally demand unpaid labour from their tenants even if they have paid the rent. Given their precarious situation, many refugees feel they cannot refuse to provide it.

Food is also one of the items that people modify to compensate for their lack of income. Their first strategy is usually to change what they eat, by consuming cheaper food items, ceasing to consume items like meat and choosing poor quality, damaged or expired food items. In rural settings, families are sometimes able to obtain permission to collect 'leftover' crops from the fields, generally produce that is not suitable for sale either because it is too small, overripe, or damaged. This option is not available in urban settings. However, people living in ITS also lose this possibility when the growing season ends.

A very common strategy is to reduce the amount of food consumed by the household, often feeding children and men first. This can lead to significant malnutrition, most frequently among women. Another common, more positive strategy is to share food (especially food aid) among family members, friends and neighbours, in the sense that those who have more contribute to those who are worse off. Finally, a common strategy used frequently by many refugees and particularly those in border regions in the Bekaa and Akkar was to shop for staples and other non-perishable foods in Syria, where prices are lower. This coping strategy is no longer possible due to the recent closing of the border. 


\section{Box 5}

'Mohammed' (not his real name) is a Syrian man who is over 30 and living in an ITS in Akkar. He and his family depend on aid money and on vegetables scrounged from the field as there is very little work near their ITS. Finding work has become even more difficult since their papers expired, as he is very worried about moving around to the different nearby towns. At one point his son got very sick in the night and so he and his wife took him to the doctor. But he was stopped by the police for breaking the curfew even though he was with his wife and son. They confiscated his papers and he had to get a Lebanese mediator who he had met through some jobs they did together to help resolve the situation.

The food and shelter insecurity experienced by the majority of refugees makes them vulnerable to exploitation, increasingly exposed to violence, and has negative effects on their health. More indirectly, the few housing options can have a deleterious effect on access to education, as proximity to a school cannot be a priority factor in selecting housing.

\subsection{LEGAL STATUS}

Historically and at the beginning of the Syrian crisis, Lebanon had a relatively open border policy. However, it is important to note that Lebanon is not a signatory to the 1951 Refugee Convention and therefore its laws and regulations are not shaped by those principles. At the start of the crisis, in the absence of allocated camps or settlements, people moving into Lebanon were free to settle wherever they wanted or could afford to go. Thus, refugee movement ebbed and flowed between 2011 and 2014, with overall numbers showing a continual increase over time. In May 2014, the Lebanese government imposed border restrictions on PRS denying entry to a majority of PRS fleeing Syria. ${ }^{22}$ It imposed restrictions on Syrian refugees in January 2015. These restrictions do not contain a category for refugees fleeing conflict or persecution and seeking safety in Lebanon, with the exception of some very limited humanitarian criteria than can theoretically be applied by authorities at the border but that in practice rarely are. ${ }^{23}$ This has had the effect of greatly reducing the refugee flows into the country. ${ }^{24}$ As of May 2015, the UNHCR also stopped any new registration of refugees, as per instructions from the government of Lebanon, regardless of how long they had been in the country.

\section{Box 6}

'Jamal' (not his real name) is a Syrian male under 30 who came to a town in Akkar about three years ago. He usually works as a painter though does other work to support himself and his wife, who he married since he arrived in Lebanon and who is now pregnant. The first time he had to renew his residency permit, the fee was paid by a foundation from Qatar; but now it has expired again and he does not have the money to renew it. He sometimes cannot avoid crossing checkpoints when he has work that is further away from his village. For the regular checkpoints, the soldiers will usually let him through and just tell him that he should renew - but when there is a pop-up one, he simply asks the vehicle to stop and turns around and comes home again. This has caused him to lose a lot of work, including a relatively steady job that he had in a much larger town. In general, all of the checkpoints make him feel like he is in a prison. Another major concern is that his marriage certificate has not been formalized, because he and his wife were missing papers. He is consequently worried that he will not be able to register their child when it is born. 
Among our respondents, nearly everyone entered Lebanon legally. Of those who entered without a visa, most are men. This is because they believed they would be turned back by the Lebanese authorities, or stopped by the Syrian army and drafted into service. Because women and children were believed to be more easily able to cross the border, they most often took the legal route, while the men would cross the border clandestinely.

Over time, however, the rules for the renewal of residency have changed frequently and become increasingly restrictive. The cost of renewal for Syrians is presently US $\$ 200$ per adult, and for refugees registered with UNHCR requires a pledge from the recipient not to work as well as a pledge from a Lebanese landlord that the person is occupying their property and that they will notify the General Security Office when the occupancy ends. ${ }^{25}$ In light of the income challenges experienced by the majority of our respondents, it is clear that fulfilling these requirements - which as noted above, have been in place since January 2015 - is almost impossible, especially for households with more than one adult member, as the cost becomes prohibitive. For PRS, there have been a series of little-circulated, inconsistently implemented General Security Office circulars in 2015 that have allowed PRS to renew their residency permits for up to three months for US\$200. Again, the prohibitive cost, coupled with fear of arrest by the GSO (General Security Office), means that few PRS have approached the GSO to renew. ${ }^{26}$ Important to underline is that the research for this study was carried out after the new regulations came into effect, and thus reflects the response of the refugees to the new regulatory framework.

While a very few families are able to renew the permits for all members, this is very rare. Another strategy adopted by some families is to renew the residency of one family member to enable them to move more safely in search of work or while going to work, even though this means they will have to violate the conditions of their permits. Almost all interviewees pointed out the 'Catch-22' situation this creates, where you need a residence to remain legal in the country and have access to a source of income, but are barred from working if you have a permit [renewed with the UNHCR registration]. A frequent rationale for renewing the residency documents of men and older boys first is that this at least allows them to cross checkpoints more safely, and that women and girls are perceived to be at lesser risk of being stopped at check points. However, this leaves the refugees subject to abuse by employers, who may threaten to report them to the authorities if they complain about their working conditions. In extreme cases, they will use this to refuse payment after work has been performed.

\section{Box 7}

'Iman' (not her real name) is a PRS woman under 30 years-of-age who lives with her parents and siblings in Chatilla camp. She and her family came to Lebanon at the end of 2012, and moved around multiple times before settling in Chatilla: 'But I didn't want to stay here, there is garbage everywhere and diseases - it's shameful to call this a camp.' She works for a local NGO and also teaches children in the afternoons. In addition to the UNRWA aid that her family members receive, hers is the only source of income since her 60-year-old father is too old and sick to work. She says that she feels unsafe in the streets, that PRL men harass her verbally and whisper crude things in her ear. She has also overstayed her residency, which is a significant source of stress. Recently she was stopped at a checkpoint and she felt terrified; she gave her ID to the soldier and when he said that it had expired, she told him that her paperwork was at general security and that she had forgotten her receipt at home. The young man next to her in the van tried to use the same excuse and had his paperwork confiscated, but the soldier handed back her paperwork with his phone number and name in it. Ever since, she tries to limit her movements as much as she can: 'But as a girl you flirt to try to improve the situation.'

Still, a large majority of respondents have expired papers, which restricts their ability to move either for work or to obtain supplies or access services. They therefore tend to stay at home 
more, and when they have to go anywhere, to take back roads or travel on foot to avoid checkpoints. Young women in particular, when stopped at checkpoints, sometimes use flirting to avoid problems, despite the fact that this presents clear risks of sexual exploitation. A further concern is that many children born to refugee parents in Lebanon are not being registered, whether because the parents do not have legal residency status in the country, because the parents' marriage is not recognized in Lebanon, or because the procedures are not properly understood. Of those who mentioned the issue, it was articulated as a concern by some with others seemingly less concerned about it relative to other, more immediate priorities.

The current legal framework thus creates significant vulnerability and sometimes direct threats. Indeed, ITS in Akkar and in the Bekaa reported raids in which men and boys are detained and the property of refugees damaged or destroyed. The restrictions imposed on employment also severely limit the ability of refugees to earn any income and, when they can find work, places them at risk of abuse and exploitation. Moving around in public spaces also becomes risky, as those whose permits have expired are subject to arrest or deportation, and may also experience abuse at the hands of the authorities.

In the case of PRS, a few respondents indicated that they moved into PRL camps once their documents expired, because they feel relatively safer there. This is in part due to the fact that there are no government checkpoints within the camps. However, as was mentioned in the section on Income, employment opportunities are fewer and living conditions tend to be worse in those areas.

\subsection{SECURITY AND SAFETY}

The safety and security of refugees can be understood as encompassing two different though not unrelated dimensions: within the home and in public areas.

Within the home, our research shows strong signs of stress as a direct result of the displacement and the difficulties experienced in terms of obtaining income, finding work and providing for the family. Children are generally described by respondents as being increasingly unruly and ill-tempered, or depressed and listless. They also describe tense relationships between couples and between parents and children of all ages. Men, but also sometimes women, resort to increased smoking to cope with the stress.

\section{Box 8}

'Rima' (not her real name) is a Syrian woman of just under 30 who came to Lebanon about three years ago with her husband and their six children. They have moved around quite a bit in the Tabbaneh area of Tripoli since arriving, preferring to stay in that area as it is close to where her husband works infrequently as a day labourer. She says that their situation is very difficult: they don't have enough money for food basics like courgettes and have tried to save money by moving into a flat in one of the least safe parts of the neighbourhood. One of the difficulties of the area is that her children are always getting into fights with Lebanese children, so she tries to keep them inside as much as possible. She also has to walk her children to school, which is quite far away and which concerns her because of the harassment she faces when coming back alone. She says that she deals with her stress as best she can, but that she's impatient and her husband even more so, especially when he thinks about income issues. According to Rima, her husband hits her when he is stressed and she also hits her children as a way of releasing stress, even if they are asking for something very simple. She says that they didn't do this when they were still living in Syria. 
These stresses and tensions tend to be expressed through more frequent and more intense arguments, sometimes involving shouting and physical assault towards women by men, toward children by men and women, and between children. This type of situation was described both by men and by women, and was usually characterized as not having existed in the household prior to displacement. The data collected for this study does not reveal particular patterns in terms of the types of respondents who report this, nor regional differences.

It appears that these behaviours may be related to unresolved psychosocial stresses or traumas resulting from experiences in Syria that have not been addressed, and perhaps exacerbated by the difficult conditions of the refugees' current situation.

Outside the home, most refugees describe feeling unsafe in their current surroundings to a greater or lesser extent. They attribute this insecurity partly to the fact that they are in a foreign land. But many also report being victims of verbal abuse by host community passers-by or sometimes neighbours, who will shout at them to go home or accuse them of 'stealing jobs', or use pejorative epithets and slurs related to their nationality, accusing women of indecency, etc. This is also the case for PRS, who are seen as Syrian both by Lebanese and by PRL and therefore treated in the same way as Syrians. ${ }^{27}$ It is worth noting that the fact that PRS indicate they feel subject to similar abuse as Syrians even from PRL indicates that there does not appear to be a sense of common struggle among Palestinian refugees, but rather a reflection of the difference or even competition existing between Lebanese and Syrians.

For both refugee populations from Syria, these tensions lead to fights among young men in the streets, as well as among children at school, and to sexual harassment for women.

\section{Box 9}

'Amira' (not her real name) is a PRS who lives in the Bekaa and who is under 30 years-ofage. She came to Lebanon with her parents and siblings three years ago, leaving Syria after their neighbourhood came under attack by helicopters dropping barrel bombs. She feels that her life has been turned upside down in Lebanon, with their family struggling to make ends meet. When she first came she thought she would finish her education, though had to give up on that so that her siblings could go to school. She then got engaged to and married a wealthy Lebanese man, and she thought it would be a marriage for life. But her husband travelled a lot for work and she was living with her mother-in-law who continually insulted her by calling her a refugee. She eventually had to leave as even though her family has nothing, it's most important to save her dignity. Now she gets looked at very negatively in the street for being divorced.

Syrian women are also targeted for abuse for a variety of related reasons. Due to their poor socioeconomic conditions, according to community members they will often require lower dowries from prospective husbands. This has led in some cases to Lebanese men marrying these women and then divorce them after a short period of time.$^{28}$ In addition, some Lebanese women resent their presence because they feel that Syrian women are 'taking their husbands'. Furthermore, as is noted in section 4.1, refugee women can be exposed to varying forms of gender-based violence in their place of employment. For example, one Syrian woman under 30 years-of-age said that she quit a job in a store because her employer was sexually aggressive to her, making it clear that he knew she was in need of money and that he would pay her for sex.

A different type of insecurity in public areas relates to the fact that some can only afford to live in neighbourhoods where there are high levels of criminality and conflict, as described in the section on Shelter and Food. Significantly, the safety of Syrian refugees is further reduced in most areas as a result of the effects of the conflict in Syria. In this regard, male refugees generally reported comments from host community members being related to the fighting in 
Syria and their presumed links to that fighting - for example, young men were taunted for 'not being man enough to go and fight' in Syria. According to interviewees, in the Bekaa the refugees are allowed to stay in relative safety in exchange for controlling their movements, which become increasingly restricted when the conflict in Syria flares up near the border or when fighting in Syria leads to funerals for local Lebanese fighters. Also, as reported by respondents, Syrian men, particularly in the Bekaa, are often suspected of being linked to armed groups fighting in Syria.

This threat is generally experienced as increased harassment from the military in most areas, except in Akkar, where there is comparatively less military presence except at the borders. In that region, the movement of Syrian men is controlled instead by municipal authorities, through curfews targeting the refugees. Similar curfews are in place in most regions, and enforced by various agents: municipal government, security forces or local Lebanese militias.

Our research also found several examples of a different type of spill-over effect from the Syrian conflict. These were cases in which events in Syria resulted in violent actions being taken in Lebanon. For example, one interviewee told about having his brother kidnapped in Tripoli in relation to something that had gone on in Syria just prior to their coming to Lebanon, and said that he had had no concrete news about him since his disappearance.

\subsection{HEALTH}

Access to healthcare was an often-cited challenge by interviewees, although this seems to affect different groups in different ways. Healthcare concerns appear to be a priority for babies and young children, pregnant women and older people, as well as for the people who care for them. Most elder children and younger adults tend not to access health services unless they have particular needs due to illness or other health conditions.

For Syrian refugees, access to healthcare is primarily through UNHCR's Public Health Centers. They also benefit from a subsidy covering $75 \%$ of the cost of life saving healthcare services. While the income challenges highlighted in the corresponding section of this report lead to healthcare costs being perceived as challenging, this is exacerbated by the fact that most Syrian refugees were accustomed to Syria's socialised healthcare system in which they had no out of pocket expenses. The co-payment they are expected to cover in their current situation is therefore experienced by them as exorbitant, and a significant barrier to access to services. This is compounded by the fact that they have to purchase their own medication, which they would have received at little or no cost in Syria prior to the conflict.

\section{Box 10}

'Karam' (not his real name) is a nearly 60-year-old PRS living in Chatilla since 2013 with his wife and children. He has severe health problems: he had open heart surgery in Syria before coming to Lebanon, and has since had several strokes; he also needs a liver transplant, but was told by the organizations he has approached that he probably has to go abroad to have the surgery and that there is no budget to cover such travel. Given the family's financial situation, he says that he can only hope that God will help him.

Meanwhile, he dreams of going home to Syria to at least die in his own house, even though he's sure that his furniture is gone and there is no electricity or water.

To cope with this challenge, Syrian refugees described travelling back to Syria to access medical care and obtain medication, where it was significantly more affordable. However, the 
closing of the border has eliminated this possibility. Some refugees reported that they now hire a taxi driver to fetch medications in Syria, even though there is typically a US $\$ 25$ service fee attached, as it is cheaper than purchasing them in Lebanon.

A more negative coping strategy consists in foregoing medical treatment and/or medication, particularly for non-life saving healthcare though also for more serious health situations. One individual injured his eye in an accident and felt he couldn't afford to seek medical attention; he is now permanently blind in that eye. A Syrian woman living in Tabbaneh reported that she has a family history of uterine cancer and suspects she may be affected, but will not seek medical attention because she knows she would not be able to afford the treatment.

For acute conditions, people borrow money and sometimes families and neighbours provide gifts of cash. This is not, however, as easy for serious chronic illnesses that require treatment. For example, one family has a young daughter that requires regular dialysis. Before the border was closed, they used to take her for treatment in Syria. Since then, they have borrowed money from a wide pool of connections, including family, friends and neighbours, both Syrian and Lebanese, to get her treatment in Lebanon - but this resource is now nearly exhausted.

Occasionally, wealthy individuals in the local community will provide financial support to help with medical expenses. There are also some religious organisations that can provide short-term assistance in particular circumstances, but these options are not available universally, and are usually provided at the sole discretion of the donor.

Our research was not able to identify significant differences by geographic area, except to note that access to health services may be somewhat easier in rural areas, especially for refugees living in ITS, as some benefit from mobile clinics that come to them once a month or so. In urban settings, people have to seek out the medical services they may need.

With regards to the quality of the services received, a clear distinction was made by our respondents. For serious conditions, they reported being satisfied with the quality of the care provided. However, they regularly indicated that they find it difficult to obtain appropriate service for more minor conditions. Many also noted that they feel they are treated rudely or disrespectfully by frontline health workers, that their concerns are not always taken seriously and that they do not always receive a full examination.

\section{Box 11}

'Yara' (not her real name) is a Syrian woman over 30 living in Akkar with her husband and two children. Her husband's family has known their landlord for 20 years, as the landlord used to come to Syria to buy furniture for his furniture store and because her husband's father used to work in the area doing construction. In 2011, she donated her kidney to her daughter, with the surgery being performed at American University Hospital in Beirut. Her daughter now goes for dialysis every month and must take a lot of medicine, which is very expensive. She talked to many NGOs to try to get financial help and also asked the Ministry of Health, both without success. Last month, she gathered money from her friend and from friends of friends to pay - but she has no idea how she will find the money in the longer term.

Many interviewees also access health services through pharmacies rather than clinics, not only purchasing medication but also seeking medical advice, as they find this is a faster route. However, pharmacists' services are not subsidised, so they are reportedly very costly.

PRS access healthcare through UNRWA, and the majority of our respondents found the level of care to be of reasonable quality, although they also considered it to be more difficult to access 
and more costly than similar services would have been in Syria. In general, PRS raised the issue of healthcare less frequently than did Syrian refugees. ${ }^{29}$

With regards to their health status, all respondents indicated significant increases in stressrelated health problems (such as high blood pressure, heart issues, ulcers), as well as psychosocial issues that have not been treated. The most frequently reported strategy to cope with stress concerns is talking to one another, which is more difficult for those whose families have been separated and for those whose social and support networks have been disrupted by the crisis, and exacerbated by the additional isolation created by the restrictions on movement related to legal status. They also indicated increased smoking and crying. Importantly, many told us they tend to take out their stress on household members, typically by shouting at or mistreating wives, children and older relatives. Young men also tend to get involved in street altercations.

The net effect of the challenges refugees experience in accessing health services is that there are a lot of untreated conditions, including mental health issues, which could have significant negative effects on these populations in the medium to longer term.

\subsection{EDUCATION}

In general, most Syrian refugee children tend to attend public Lebanese schools in the afternoon shift (the morning shift being usually reserved for Lebanese children). Some children in ITS attend school in tents on the site of the ITS. Most PRS children attend UNRWA schools.

Around the age of 15 , many families indicate it makes more sense for the household to have the child go to work. A common reason given for this decision is that they find the quality of the education rather poor, and that the income the child might generate is a better use of their time. Other times, it is due to the young person finding the schooling too difficult or the school environment unappealing. That said, the families generally see this decision as being difficult and unfortunate.

A significant challenge identified by multiple interviewees relates to the fact that public education in Lebanon includes a portion of English and/or French, whereas in Syria education took place exclusively in Arabic. Many Syrian children and particularly those who are older therefore experience more difficulties keeping up with the curriculum, and this is often given as a reason for teenaged children leaving school. Families are also uncertain as to the possibility of having any credentials or diplomas recognised in Syria after the end of the conflict.

Access to schools is sometimes cited as a challenge, in so far as the refugees cannot always choose their shelter on the basis of the distance to schools. As such, they sometimes face additional costs to cover transportation, including expensive school buses. Many others have to walk to school, sometimes for up to an hour. Some children walk to school on their own, which poses safety concerns with respect to road safety as well as negative interactions with people en route. In other cases, accompanying the children to and from school on foot is an additional responsibility usually taken on by mothers.

It should be noted that concerns about access to education or its quality was not a first order concern raised by any of our interviewees. When it was mentioned, it was almost exclusively by women, which is unsurprising in a cultural context where they have primary responsibility for childcare. 


\subsection{CROSS-CUTTING CHALLENGES}

There were several challenges that did not fit within one of the themes covered so far, or in the case of some that were applicable to all the themes. We have therefore decided to treat these cross-cutting challenges separately in their own section. The three cross-cutting challenges are: time, displacement and third country relocation.

\section{Time}

One of the hypotheses in the early stages of this study was that those refugees who had arrived in Lebanon in the early stages of the crisis in Syria would have somewhat better conditions than later arrivals, in so far as they might have been able to bring more of their assets with them, or they might have been able, over time, to build relationships and improve their situation. However, our study finds no discernible difference among these groups.

Indeed, the vast majority of refugees from Syria that we interviewed, regardless of the length of time of their presence in Lebanon as refugees, tend to be engaged in similar work as day labourers, without a regular employer, and they therefore have not been able to build relationships that might afford them an advantage over more recent arrivals for the purposes of obtaining work. Similarly, obtaining shelter is no easier for those who arrived earlier, in so far as the cost of rent has increased equally for all tenants. Thus, we find that the quality of accommodation reflects the tenants' ability to pay, on the basis of income, rather than on the length of their presence in Lebanon.

Another dimension of the time issue is related to the refugees' perceptions of their situation, more specifically whether they perceive things as getting better, worse, or staying the same, as well as how they perceive their situations going forward. Of the interviewees that compared their present situation to earlier, there was a tendency amongst all respondent groups to characterize things as getting worse. This could be the result of getting increasingly worn down by the difficult circumstances, as well as due to changes in their actual situation such as more challenging legal status issues or increasingly poor relations with the host communities. Relatively few interviewees spoke about the future, underlining the extent to which the overwhelming challenges of the present preclude such planning. Of those who did speak about it, there was a strong tendency to express hopelessness or even desperation. The former usually emphasised their desire to return to a peaceful Syria one day, though many also mentioned that they could not see that happening anytime soon; the latter - more often men and usually under age 40 - said that they were considering options such as third country relocation (see section 4.7 - Cross-Cutting challenges: Third Country Relocation).

\section{Displacement}

One of the fundamental realities of the lives of refugees is the overarching challenge caused by displacement itself. Indeed, it must not be forgotten that refugees have had to leave behind their homes along with most of their belongings. In many cases, members of their families have been left behind in a situation of conflict. The refugees now find themselves in an unfamiliar country, often cut off from their social and familial ties. All of these factors mean that they are under great emotional stress, often exacerbated by unresolved trauma resulting from the conflict situation they have fled. Indeed, many of the refugees we interviewed had experienced, either personally or through family members and acquaintances, torture and unspeakable deprivation prior to arriving in Lebanon.

As a result, most of our respondents are experiencing high levels of anxiety and uncertainty, and almost all of them experience their current situation as incredibly difficult to bear. A noteworthy component of this that was remarked upon by a cross-section of respondents is the 
lack of respect that they feel they are accorded in their daily life and especially in interactions with government officials and with many international organizations, as well as the extent to which their circumstances are an assault on their dignity. This clearly has spill-over effects, as was discussed throughout the previous sections of this report, with regards to health (mental as well as physical) and family cohesion. In all our interactions with refugees from Syria in Lebanon, interviewees expressed, to varying degrees, a sense of constant worry, of loss of dignity and self-esteem, and of the precariousness of their situation, so that they feel unable to plan for the future, even in the very short term.

While none of this represents a clear protection challenge, as defined for the purposes of this study, it nonetheless represents the underlying landscape against which the challenges discussed here must be contextualised.

\section{Third Country Relocation}

The experience of Syrian refugees in Lebanon is overall extremely difficult, presenting many livelihoods challenges and protection concerns. An important coping strategy is to seek third country relocation. This, according to our interviewees, is one of the most difficult decisions they face. Indeed, a broad cross-section of refugees said that they would like to go home to Syria, a wish that was usually expressed with longing about their better living circumstances prior to 2011 and regret yet certainty that it was impossible to imagine doing so in the foreseeable future because of the fighting and generalized insecurity there. A few respondents would like to stay in Lebanon for the duration of the crisis, because they think this would make it easier for them to return home. However, many have given up hope of ever returning to Syria, and find their situation in Lebanon unbearable. They therefore see the option of relocating to Europe or to another country such as Canada or Brazil as their best hope for a better life.

\section{Box 12}

'Fatima' (not her real name), a nearly 30-year-old PRS living in Nahr al-Bared, came to Lebanon for the first time in 2012 with her husband and four children, then went back to Syria for about a year before coming to Lebanon again about a year ago. She says that she and her husband decided that they would try irregular migration as their situation was so desperate. The original plan that was heavily pushed by her husband was for him to take the 13-year-old to Germany and to set him up there, before returning to get his wife and the other children. But the 13-year-old felt nervous about going alone, so the husband also took the 8-year-old when they went by boat from Syria to Turkey and then by another boat to Italy. Near the Italian coast, they were put into smaller boats and pushed away from the main boat, to wait for the Coast Guard to come and pick them up. They were eventually picked up and taken to a camp in Italy, which they walked out of and took a bus to Germany. Her husband has not been able to send much money as he is supporting the three of them in Germany, and she has been living with her parents while waiting for him to be able to sponsor her to come.

Nearly all refugees have registered, or sought to register, with either UNHCR (for Syrian refugees) or UNRWA (for Palestinian Refugees from Syria), which is a prerequisite for admissibility to third country relocation programmes. Nearly none of the interviewees in this situation have yet received offers of relocation. Most have also made the round of the various embassies in Beirut, to apply for refugee status in the various countries. They find the process frustrating and difficult, in particular because of the cost involved in travelling to Beirut and as a result of the challenges to their mobility resulting from the precariousness of their legal status (as was discussed in detail in the section on Legal Status). Similarly, the vast majority of our 
respondents indicate that they do not understand the criteria for selection or that they find them to be applied in an arbitrary manner, and find the length of the processing times difficult to deal with. The challenges facing the refugees are moreover complicated by the fact that many are hesitant to have their families be separated. For example, two respondents indicated that they had received offers of relocation to Germany. However, they had been forced to turn them down, because they did not cover their whole family - in one case, a widowed daughter and in the other a young adult son, had been excluded from the offer.

The perceived slowness of the legal process has led many to seek alternative, irregular routes for migration. Of those respondents who discussed the issue, the majority have multiple family members and/or acquaintances who have taken this option to go to Europe. Most of them went to Egypt while visas were available to them, or go through Sudan. From there, they have taken an overland route driving through the desert for 12 hours to four days, to the Libyan coast, where they seek to embark towards Italy. Alternatively, especially for Syrian refugees, they might head towards Turkey and onwards to Greece (at the time of the data collection, the largescale movement through Turkey and the Balkans had not taken place yet).

Among our respondents, it appears that PRS have been taking the option of irregular migration slightly more often than the Syrian refugees. The reason for this difference is unclear, but may be related to the fact that the international response to the Syrian crisis has primarily focused on assisting Syrians to relocate, while few if any provisions are being made for PRS. It is also more prevalent among young men, though is certainly not exclusive to them since there were examples of several family members going at the same time including young children and even pregnant women. We did not find any mention of women undertaking irregular migration alone. In the case of families, there were multiple examples of men who had gone ahead of their wives and children (and had sometimes gone with or been followed by male children of various ages), with the aim of sponsoring their wives and daughters to come to Europe through official channels. Those interviewees who were not considering irregular migration tended to say that it was because they either hoped to go back to Syria or because they still had family members in Syria who they would feel like they were abandoning.

\subsection{CONCLUSIONS: REFUGEES FROM SYRIA}

An important pattern running through the coping strategies identified in this study was the use of networks. Refugees, both Syrian and PRS, tend to use familial, kinship and other social networks to find jobs and shelter, to maximise their security and protect themselves against threats to their safety.

It is noteworthy also that there are very few differences among the different categories of respondents, as well as among the different regions included in this study. Where differences occur, they tend to be associated with the variance in services and support available to Syrian refugees as opposed to PRS. Similarly, there are differences between urban and rural areas, but these are replicated, proportionately, in all the regions under study, and therefore there seem to be few patterns emerging on the basis of proximity or distance to Syria, or of the majority ethnic or religious group in the host community.

When considering the livelihoods challenges and the respective protection concerns analysed in this report, it seems significant that almost all interviewees cited their legal status as a significant challenge, and often as their major challenge. Increasing restrictions on their ability to cross the border, to move freely within Lebanon and to access work have had the effect of negating many of the coping strategies refugees had been using to access income, food and health services.

The inability to work legally and the difficulties they experience in obtaining sufficient income have obvious consequences with regards to securing suitable shelter and to feeding themselves 
and their families, as well as to access health services and, to some extent, education. This leaves them extremely vulnerable to exploitation and abuse in the form of unpaid or significantly underpaid labour, sexual exploitation and sexual violence. They also face deliberate discrimination in the form of illegal curfews, harassment from security forces, and are subject to verbal and occasional physical abuse.

An important concern for the researchers that emerges from the fieldwork relates to what appears to be an unmet need regarding the psychosocial health of refugees. When this issue was discussed by respondents, they indicated that only extreme cases of depression or other mental health challenges were receiving any care, and this infrequently and for short periods of time. Yet we observed high levels of distress among respondents, almost all of whom reported experiencing high levels of stress, loneliness and alienation, and many had experienced highly traumatic events prior to their decision to leave Syria. Related to this, many also spoke about the lack of dignity of their present circumstances and the lack of respect that they experience in their daily life.

\section{RESEARCH FINDINGS - HOST COMMUNITIES IN LEBANON: COMPETING FOR SCARCE RESOURCES FOR ALREADY VULNERABLE POPULATIONS}

In the Context section of this report, the very high number of refugees that have come to Lebanon since 2011 was detailed: nearly 1.3 million registered refugees and an estimated hundreds of thousands of unregistered refugees, representing some one-third of the total Lebanese population prior to the outbreak of the crisis in Syria. A very significant proportion of these refugees are highly vulnerable, and as was detailed in section 4 of this report, living in conditions of poverty and insecurity.

The impact of the refugees from Syria is felt throughout Lebanon and Lebanese society. Yet the impact is experienced differently by different segments of society, and is disproportionately impacting upon the lower socio-economic segments since they are the part of the host communities who are co-living with the refugees. This is not to minimize the impact for those segments of society that are higher on the socio-economic ladder - yet for these people, the impact tends to be more distantly felt, experienced at an existential level of concern and disquiet, as well as more directly by seeing refugees in the street and living in fields and through interruptions in public services such as electricity. They are not then directly affected in their employment or shelter situations - since they are not competing directly with refugees in these areas - or in their access to services.

As we move further down the socio-economic ladder, the directness of the impact tends to increase. At this level then, small shop owners and business people are competing with refugees from Syria (and hiring refugees), while family farms have them living on their land and are hiring them to work in the fields.

Moving further still down the socio-economic ladder, host community labourers are competing with refugees directly for work, while residents of the poorest neighbourhoods such as Tabbaneh in Tripoli and Chatila in Beirut, as well as in poor rural areas and towns in regions like Akkar and the Bekaa, are living closely with the refugees. They are competing with them for 
shelter and seeing their rents rise as a result of the increased demand, walking side by side in the busy streets and shopping in the same shops as them, often sharing their schools with them - albeit usually in different shifts for Syrians - and otherwise interacting with them on a daily basis. Important to note as well is that most PRL host communities tend to fall within this segment of the country's population, as a result of their overall weaker and more precarious socio-economic status in Lebanon.

It is the impact on this lowest segment of society, which represents a bit over one third of the country's total population that the research study has primarily focused on understanding. ${ }^{30}$

The situation of poor Lebanese was already very difficult before the onset of the 2011 crisis. According to a 2008 study by the International Poverty Centre, about 300,000 people in Lebanon were unable to meet their most basic food and non-food needs. ${ }^{31}$ At the time, they were suffering from precarious employment situations, low-income levels, poor housing quality, poor access to health care as well as poor quality public education, and poor services and weak infrastructure overall (including water, electricity, and transportation). The situation of poor PRL was also already very difficult prior to the 2011 crisis, with an unemployment rate that was estimated to be around $56 \%$, two thirds classified as poor and an occurrence of extreme poverty that was four times higher than in the Lebanese population. ${ }^{32}$

As we will see in the following sub-sections, interviewees feel that their situation has grown markedly worse in all of these areas since 2011, and that the presence of the refugees in overwhelming numbers has exacerbated what was already a very difficult situation. For a population that has long felt alienated from and forgotten by its own government, the presence of the refugees and what they characterize as their own resulting reduced circumstances, coupled with the aid that has flowed in for the new arrivals but has largely bypassed the host communities, has given rise to a sense of frustration and a strong tendency to blame the refugees. This frustration and anger was a common thread running through most of our interviews with Lebanese host communities, as were more specific ways in which the refugees' presence has impacted upon them.

As was noted in section 3, Methodology and Approach, this section of the report presents the host community's challenges in the same order as in the refugees section for the sake of easier comparability. Thus it focuses on income, shelter and food, security and safety, health, and cross-cutting challenges. Differences between particular respondent groups - Lebanese or $\mathrm{PRL}$, male or female, 30 and under or over 30 , and particular geographical regions - are highlighted whenever relevant. If not highlighted, there was no discernible difference on the issue under discussion. At the end of the section, we present some overall conclusions in regard to the host communities.

\subsection{INCOME}

\subsubsection{Finding Work}

One of the most significant challenges for the host communities is in regard to work. More specifically, almost all host community members, though particularly men, noted that the arrival of so many refugees has had negative repercussions in terms of the availability of employment and in terms of the amount of money that they can earn. Those particularly impacted are host community members who are doing casual, unskilled labour such as construction and agriculture, since these are the fields of work where refugees from Syria tend to work. Yet even for host community members not working in these sectors, there was a discourse of blaming the lack of steady work and the low wages on Syrian nationals, with interviewees invariably saying that Syrians will work for half the price of what a Lebanese would charge. Some interviewees also noted that the employment situation had not been good prior to 2011, and that the arrival of 
so many refugees was therefore simply compounding what was already a difficult set of circumstances.

PRL were slightly different than Lebanese host community members because of their more vulnerable employment situation. Thus while some said that there was less work because 'Syrians' - meaning PRS and Syrians - will work for less money and thus take the available jobs, almost all spoke about a generalised lack of work, with many also saying that this was a situation that had existed for PRL for a long time. There were no clear patterns in terms of which PRL made these comments, though it was particularly men who spoke about the employment situation and younger men who blamed the increased number of Syrian nationals.

Comparatively speaking, PRL seem to be working relatively more in Beirut as a result of their being relatively more work opportunities compared to camps such as Nahr al-Bared or Jaleel, where there is very little work available.

Related to this, host community small business owners noted that the prices they can charge for their goods and services have gone down or that the number of clients has decreased, due to refugees from Syria undercutting their prices. They explained that refugee shop owners are able to charge less by both living in and selling out of shop fronts, thereby combining their business and shelter rents into one. They also do not pay business taxes according to interviewees (since their stores are often illegal). For small businesses like construction companies, Syrians simply charge less because they are willing to accept lower wages. Some also said that Syrians would bring construction materials across the border from Syria, where they are cheaper. This practice has decreased recently as a result of the border restrictions, though reportedly it remains an issue in Akkar.

\section{Box 13}

'Saad' is a Lebanese man over 30 living in Sabra in Beirut and working as a taxi driver while his friend 'Hassan' (not their real names) is also a Lebanese man over 30 living in the same neighbourhood and working irregularly doing labour jobs. They agree that things have changed a lot since before 2011, that the major difference is the number of 'foreigners' that have arrived and that the Syrians have taken their jobs because they get paid less; even the price of renting a vehicle to drive as a taxi has gone up a lot because Syrians will pay more. Yet they feel that many of the refugees are doing well, citing as proof that Syrians own stores and butcher shops and bakeries, and moreover that Syrian refugees are also getting help from other organizations. Overall, there is a feeling that they are exaggerating the situation in Syria, that it's fine in many of the big cities like Damascus and Aleppo. They both blame the Lebanese government for not enforcing the rules on Syrians; says Hassan, 'I cannot find a job or a decent house.'

The coping strategies adopted by host communities in regard to this situation involve reduction in spending on non-essentials such as clothing, as well as opting for less expensive foods. They are also forced to accept lower salaries and to look harder for work, for example by working their networks more assiduously. These coping strategies are negative in that they chart a course of increasing poverty and greater vulnerability. They also risk fuelling negative intercommunal interactions.

The obverse side to the income concerns expressed by host community members is presumably that employers, the overwhelming majority of whom are Lebanese, are benefitting from an increased supply of labour and decreased labour costs. Indeed, this phenomenon was remarked upon by several interviewees, including a shop owner in Akkar: 'There is no pressure in the town to hire a Lebanese rather than a Syrian, there is a certain tolerance of it.' This would 
seem to some degree to offset the negative impacts of the economic instability and overall depressed economic situation in the country, at least in the short-term, and at least for this particular segment of the population. Related to this, it was interesting that there did not seem to be any widespread social condemnation of employers by host community members for paying lower wages or for firing them in favour of hiring Syrians; rather, most interviewees criticised the Syrians.

\subsubsection{Aid}

The other pole of the income challenge for host communities is in terms of aid distribution. Almost all host community members noted that aid has tended to be distributed on an identitybased rather than needs-based model, and that poor Lebanese who are also in very difficult situations are not receiving aid. From the point of view of PRL, there is a sense that what was already a very limited amount of aid being given to them has been cut by the arrival of PRS, and that new aid such as rent subsidies has been given to PRS, and has not been made available to PRL. Multiple host community interviewees also said that refugees are using their aid income stream as a means to supplement and thus make possible the lower wage demands that allow them to monopolize the available work. Interestingly, several Lebanese interviewees in different regions said that they have ideas about what kind of programming would be most effective, though no one had ever consulted them. Overall, the aid situation is experienced as profoundly unfair and unacceptable by host community members.

The coping strategies in regard to aid distribution centre on attempting to pressure organisations to also distribute to host communities, and some interviewees, exclusively men, even mentioned they could threaten to block aid that is not distributed on a needs-basis (a threat that was heard in multiple regions though especially in Tripoli and the Bekaa). The ability to do so seems relatively greater in more controlled settings such as in closed Palestinian camps; in neighbourhoods with complex power dynamics that must be negotiated and come to terms with by aid organisations, such as Tabbaneh; and in rural areas of the Bekaa and Akkar, where municipalities and local authorities have greter ability to control access. It is relatively harder to do in less controlled urban settings such as in Beirut.

These coping strategies are not necessarily negative or positive per se. Yet the possibility of negative effects does exist if aid was not disbursed to both communities. To take one example, violent clashes were reported between Lebanese host community members and Syrian refugee residents of an ITS in the Bekaa, as a result of a sense of grievance on the part of the refugees that they were being deprived of much needed aid and moreover that the Lebanese were being treated with more respect in the distribution process since they did not have to wait in line for their aid for hours. There are other examples of reverse situation. In general, depriving people of access to needed aid - or if there were perceptions that this is happening -, clearly has negative protection impacts both in terms of responding to needs and in regard to fuelling intercommunal tensions.

\subsection{SHELTER AND FOOD}

Similar to income, many host community members said that the arrival of so many refugees has meant an increase in the price of rent for shelter and a decrease in the availability of alternative shelter options. This was equally remarked upon by men and women in different regions, and was raised as an issue by host community members who are directly affected because they themselves are renting (and thus seeing their own rent rise or their choices decrease) as well as by host community members who own their home and who are consequently not directly affected. 
The coping strategies for this are to try to increase income, subject to the limitations that were outlined in the previous section, or to cut expenses to be able to afford the increased rent. It also necessitates looking harder for a new shelter option than would have been necessary before 2011. Another strategy is to move to less expensive shelter, which in urban areas usually means lower quality, smaller shelter options (as was described in the corresponding section 4.2 - Shelter and Food, regarding refugees). Cutting expenses and moving to less expensive shelter as coping strategies increase the vulnerability of host community members, since they represent a move toward conditions of greater poverty and an overall poorer living situation. They thus represent protection concerns.

Another aspect of the shelter issue is the very high number of host community members who have rented out a building, flat, room or space for tents on their land to refugees. Here, there can be benefits in terms of gaining previously unavailable income. Yet there are also potential drawbacks, for example in terms of increased crowding as well as having conflictual interactions with tenants whose circumstances mean that they are chronically late or unable to pay rent and whose living arrangements might not be in line with the landlord's preferences. This risks giving rise to protection concerns because of the possibility of greater tensions and conflict between host communities and refugees.

In addition to mentioning the challenge of shelter, many female interviewees said that the price of food had gone up significantly as a result of the greater number of people buying, for basics such as courgettes and tomatoes but also for items such as rice and baby formula. This has led to shortages in some areas, and was particularly noted in the rural Bekaa by some respondents.

The coping strategies for this challenge are to change the mix of food being consumed to focus on less expensive items, as well as to cut costs in other areas and to attempt to increase familial income. This could be seen as a negative coping strategy to the extent that it is forcing more host community members to join the ranks of the 300,000 people in Lebanon who are unable to meet their most basic food and non-food needs.

At the same time, the increased food prices and greater number of consumers represent a boon for host community shop owners. For example, one Lebanese grocery store owner in Akkar said that he had seen a 5\% increase in sales and that other shops near him had seen a greater percentage increase. The shop owner also said that the greater number of people buying in the shops since 2011 has sometimes led to overcrowding, frustration and tension between host community members and refugees, especially when food aid coupons are disbursed at the same time of the month as poor host community members get paid, with the consequence that both groups converge on shops to replenish their homes at the same time.

\subsection{SECURITY AND SAFETY}

A challenge that was brought up by most host community members is their generalized sense of feeling less safe in the street and in public. This issue was highlighted more frequently by interviewees over 30 as well as by women of all ages, and was a theme that emerged in all regions of our study. Some interviewees traced this feeling to the number of strangers that are in the street, while others living in urban areas perceived an increase in petty criminality since 2011.

Another, more concrete aspect of this was highlighted by some young men, who described increased tension in the street with incidents of verbal and even physical confrontations between refugees and host community members. PRL in Nahr al-Bared particularly noted this, as did young host community males in Beirut and especially in Tripoli. Such incidents have obvious protection concerns in terms of possible violence and increasing inter-communal tensions. 


\section{Box 14}

'Sabeen' is a PRL woman under 30 living in Ayn al-Helweh in Saida while her friend 'Ranim' (not their real names) is an over $30 \mathrm{PRL}$ woman also living in the camp. They both find that things have changed significantly since before the arrival of Syrian refugees, that joblessness has increased, that rents have gone up and that there is more poverty and overcrowding now. They say that a coping strategy of the PRS is to send their children out of the camp to work as they won't get stopped at the checkpoints. They add that poor young PRS women, of 14 to 16 , are marrying much older PRL men - and while this was to some degree occurring before 2011, it is much more prevalent today. The two women's sense of security has also been affected: whereas before they would go and visit with friends, now they're worried that there could be more fighting and that they could get caught up in it. They furthermore observe that the young men are fighting a lot, with the PRL accusing the PRS of having stolen their jobs and of taking up their space. According to the older woman: 'I would prefer that our youth emigrate by sea rather than stay in the camps; here they are dead, they aren't living at all. Since the crisis started, the pressure has become too much.' Both women have many family members who have left by sea.

A surprise finding was that the increased pressure on and stress experienced by host community members, stress that in certain aspects mirrors the pressure on refugees, does not appear to have led to a rise in domestic tension or violence based on the fact that no interviewees brought up the issue.

Coping strategies for the security and safety situation include going out less at night - a strategy that women in particular have tended to adopt - and to keep children inside more. These strategies do not appear to raise any immediate protection concerns.

The generalized sense of feeling less safe has a further dimension in the Bekaa and Akkar. There, respondents reported that concerns about the nearby fighting in Syria spilling over the border has been translated into a tendency to perceive refugees, especially men, as potentially linked to this fighting, or as supporters of specific groups in the conflict. Some Lebanese interviewees in the Bekaa furthermore expressed a feeling of disquiet about the very high number of refugees relative to the number of Lebanese, which they feel could result in a deterioration of the situation, to their detriment, should the refugees decide to rise up in any way. They link the high numbers of refugees the need to control them better.

Related to this, several Lebanese respondents in the Bekaa said that they and others are concerned about the type of aid programs that organisations might put in place. More specifically, they said that they would be resistant to aid that seems to be aimed at making the presence of the refugees permanent or at attempts to integrate them into the Lebanese community, and indeed that they could very well imagine such aid programming being blocked by host community members. Such possible resistance, coupled with the threat of resistance outlined in section 5.1.2, could of course have significant implications for programming and for how programming should be designed.

The coping strategies adopted in the face of this situation revolve around imposing more control on the refugees. This control takes the form of curfews for refugees after $6 \mathrm{pm}$, which our data found to be widespread in the Bekaa and Akkar. In addition, security has tended to be buttressed whether by municipalities hiring and deploying more police officers to maintain the peace in Akkar, security personnel or political party representatives maintaining a visible presence around the refugees in the Bekaa, or young Lebanese seeking to make their strength known and to intimidate the refugees by driving by ITS and making verbal threats or even shooting weapons, again in the Bekaa. 
These various aspects of the security and safety situation and the coping strategies adopted in response give rise to significant protection concerns, primarily for the refugees. They point to the use of control, coercion and even oppression to maintain calm, as well as more generally the raw nerves and marshalling of resources that could quite easily lead to more widespread violence between host communities and refugees.

\subsection{HEALTH}

A concern that was discussed by multiple host community members, albeit one that was invariably presented as being less urgent than issues such as income, was related to health. For these interviewees, the number of refugees and the conditions in which they are living has created public health concerns such as lice, scabies and respiratory infections that could spread to the host communities. Several also mentioned that they are concerned about the possibility of more severe public health issues arising, such as typhoid and cholera. The popular level concerns related to health expressed by multiple interviewees was given some credence by one interviewee, a doctor in the Bekaa region.

One of the primary areas where refugees and host community members come together is at schools. Multiple interviewees mentioned their satisfaction with the school system keeping Syrian children separate from Lebanese children for reasons of health, and also described making a greater effort to put their children into private schools where they will not come into contact with Syrians, again for reasons of health.

\subsection{CROSS-CUTTING CHALLENGES}

\subsubsection{Changes in the Living Environment}

For host communities in Lebanon, the number of refugees from Syria in the country has had a significant impact on their daily living environment. Host community interviewees spoke about the effects of overcrowding, of increased noise, and of an overwhelmed infrastructure that is unable to cope with the number of people. In making these observations, they linked them to the arrival of people from Syria, though some also acknowledged that things were not good in this regard prior to 2011. Notwithstanding this latter observation, it seems clear that the arrival of so many people in so short a period of time has had a marked, strong impact on daily life in the country and moreover that the situation is generally felt to be getting worse.

\section{Box 15}

'Noor' (not her real name) is an over 30 Lebanese woman who lives in the Tabbaneh neighbourhood of Tripoli with her husband and four children, in the house that she and her husband own. She says that she feels less secure since 2011, though things are a little better since the army came into the neighbourhood recently. A big part of the problem, according to Noor, is that 'there are too many Syrians; they ran away from their country and we don't have the resources to support them, especially because there was already so little before.' A major change that she has noticed is that there is less frequently water and electricity at home, and the water point is always crowded with Syrians. The price of basic goods has also increased, for example of tomatoes and courgettes. Overall she says that she is very supportive of Syrians and that she doesn't discriminate. 
Multiple interviewees who work for the municipalities in rural areas of the Bekaa and Akkar noted that sewage treatment facilities are overwhelmed or being bypassed, contributing to the pollution of waterways and of the environment more generally. Host community members in both rural and urban areas noted the poor water quality, as well as overcrowding at water points and decreased frequency of availability overall. Issues with water quality were particularly noted in Chatila, where the arrival of some 40,000 new people since 2011 has caused the already poor water quality to deteriorate significantly. ${ }^{33}$ Chatilla, as well as neighbouring Sabra, were also notable for the number of respondents who observed that the increased number of people in the area's tiny streets has meant a noisier daily environment and greater overcrowding in the streets, contributing to overall stress and fatigue. Access to water was remarked upon as an issue in Tabbaneh in Tripoli, where several people said that there are increased lines and therefore tensions at the water points, and that this was primarily due to the high number of Syrians at them. The greater frequency and the longer duration of cuts in the electricity supply were also noted by multiple interviewees in various regions. ${ }^{34}$ As well, interviewees in both urban and rural areas said that there is more garbage around and that it is not being picked up frequently enough. Landowners and host community members near ITS were particularly frustrated about this.

These various infrastructure challenges fall particularly hard on municipal governments, which are often unable to cope with the situation. Interviewees working with municipal governments in the Bekaa and Akkar, as well as several small shop owners, noted that the tax burden falls disproportionately on Lebanese because Syrian refugees do not pay taxes and even Syrians who run small shops do not pay taxes.

The coping strategies for this situation are very limited. At an individual level, the vulnerable host community members must simply bear the situation, which represents a protection concern at the level of increased poverty as well as in terms of their dignity and integrity as human beings. From the point of view of addressing it in a more organised, collective fashion, the municipalities attempt to reassign resources and to tap new sources of funding. Related to this, several people highlighted that some aid organisations have worked to improve water supplies and waste treatment and that such aid is appreciated because it benefits both refugees and host communities. Yet overall, such strategies are insufficient, leading to a deterioration of the living environment.

\subsubsection{Perceived Breakdown in Social Mores}

A significant concern for many female host community members, both Lebanese and PRL, was their sense that Syrian women are 'stealing their men'. ${ }^{35}$ This perception seems to be based both upon popular rumour, as well as on concrete examples of known individuals to whom it has happened.

In general, there are two types of concern in this regard. The first is voiced by Lebanese and PRL women in the over 30 age group, who speak about their concern that their husband will leave them for a younger Syrian or PRS woman, leading to the breakup of their marriage. ${ }^{36}$ This concern is compounded by the fact that some Lebanese men also threaten their wives that they will leave them for a younger Syrian woman. Moreover, multiple interviewees described married Lebanese men who married Syrian women for a few months before deciding to divorce them and return to the family home. All of these circumstances have a significant impact upon the host community members' domestic circumstances, as well as on perceptions of refugees and thus inter-communal tensions.

The second concern is related to unmarried Lebanese men marrying Syrian women. For the men, at least part of the reason for marring a Syrian woman is that Syrian women and their families are more willing to forego a dowry or to demand a much smaller one as a result of their situation of vulnerability, thereby significantly reducing the prohibitive costs of getting married. From the point of view of host community females, this perceived trend is experienced as very 
threatening since they worry they will not be able to find a husband as a result. This fuels negative stereotypes as well as open hostility.

The coping strategies for this situation by host communities is relatively limited, and seems to largely centre upon targeting Syrian and PRS females for verbal abuse. These coping strategies do not presently give rise to any protection concerns from the point of view of host communities, though they are affecting refugee women at present, and in the longer term they could represent a flashpoint for conflict between refugee and host community members.

\subsubsection{Overall Sense of Frustration and Fatigue with the Situation Post-2011}

Many interviewees said that when the crisis first broke out, they had felt a sense of sympathy for the refugees and that overall the situation was bearable. But over time and as the number of refugees continued to climb, this feeling has been heavily eroded. Today, there is a generalized, inarticulate feeling of frustration directed toward the refugees as a result of the impact of their presence in Lebanon. Many interviewees spoke in varying ways about the sense that there are simply too many refugees; that they should leave the country and go home. Some also expressed support for the recent governmental restrictions on the refugees' legal status, and a wish that the government would do more to enforce the rules dating from earlier this year. Even those who were more moderate in their views and understanding regarding the plight of the refugees felt that the situation was simply too much and that things could not continue as they are now. This point of view was shared amongst nearly all host community members, in all regions. Worth noting as well is that the hypothesis that there would be a sense of common cause among Palestinians was not borne out by the data; indeed, when PRL specifically talked about PRS (rather than lumping them in with all Syrians), many said that they had had a relatively easy time of it back in Syria since they had very few restrictions compared to Palestinians in Lebanon. ${ }^{37}$

There is no particular coping strategy for this challenge among Lebanese host communities since it is such a generalized feeling of frustration. It seems likely however that it contributes to safety and security issues since it could fuel verbal or even physical targeting of refugees given that they are being perceived as the root of the problem. Such a coping strategy is quite clearly negative for the refugees. Yet at the same time, it is interesting that host community members did not agree that refugees were singled out or targeted. Indeed, multiple people in all of the study's regions said that they are treated pretty much the same as host community members on the street.

One coping strategy that has been increasingly adopted by PRL is irregular migration. Our data showed that many PRL seem to have reached a breaking point where what was already a very difficult situation - prior to 2011 - has tipped over into unbearable. Many are thus making the difficult decision to migrate to Europe, usually by boat leaving from North Africa but also by taking boats to Turkey and then heading toward Europe.

When searching for patterns in the data regarding who is going, what was striking was how widespread the practice is. That is, multiple PRL over 30 as well as 30 and under, men and women, and in the different regions considered in this study described immediate and extended family members who have gone, sometimes pointing to the particular experiences of an aunt or a brother, sometimes just giving numbers: that they know 10 people including cousins and aunts and uncles; that they know 15 people, including some who drowned. Among the PRL interviewees who spoke about irregular migration, more were considering it as an option than were not considering it as an option. A further dimension of the issue of irregular migration for $\mathrm{PRL}$ relates to the associated costs, which according to multiple interviewees is in the neighbourhood of US $\$ 5,000-\$ 7,000$ per person, which is an amount most people don't have easily available. 
Given the very significant risks of undertaking irregular migration, including the hazards of the journey, the unscrupulous people smugglers and traffickers, and the uncertain future that awaits them in Europe if they arrive, it clearly represents a coping strategy which generates/implies strong protection concerns.

\subsection{CONCLUSIONS: HOST COMMUNITIES IN LEBANON}

Overall, the host communities do not appear to be facing situations associated with major protection threats. Rather, their experience is characterised by an overall degradation of living conditions and livelihoods opportunities. This is especially the case for the host community populations that are the poorer, more vulnerable segments of Lebanese society, including PRL communities, who find themselves competing with a large influx of refugees for jobs, shelter and resources that were already difficult to access prior to the onset of the crisis.

This situation has led to more precarious and less secure income, which impacts upon their ability to access or maintain adequate housing and food. While no respondents in this category indicated that the presence of refugees has had a negative effect on their own ability to access health or education services, they do perceive the refugees from Syria as presenting a threat to public health in general and in public schools in particular.

As a result of this perceived displacement, coupled with the very real increased difficulties and deterioration of the living environment, most members of the host communities experience a strong sense of frustration and resentment towards the new arrivals, who they hold responsible for the situation. The ensuing antagonism fuels the multiplication of negative stereotypes and hostility directed at the refugees, which increasingly translates into verbal or physical abuse, and creates a constant underlying tension among the two communities. This is further exacerbated by the fact that most refugees receive some form of aid from international and local NGOs. The majority of members of the host communities in all the regions covered by this study expressed a sense of injustice in this regard, because they feel that their own situation is no better than that of the refugees, and yet they are left out of the distribution of aid. Even those interviewees whose circumstances are better than those of the refugees expressed a sense of injustice at the fact that poorer host community members are not receiving aid.

The coping strategies adopted in response to these circumstances do not generally appear to us to present major protection concerns for the host communities, with the notable exception of PRL in some of the camps who are undertaking or planning to undertake the perilous journey to Europe in irregular conditions. However, the majority of the coping strategies do raise concerns for the protection of the refugees, who risk becoming the scapegoat not only for the current difficulties but also for more longstanding grievances of the more dispossessed and vulnerable segments of Lebanese society. 


\section{APPENDIX - LIST OF DOCUMENTS CONSULTED}

\section{EVALUATIONS, ASSESSMENTS, ANALYSIS REPORTS}

Agency for Technical Co-operation and Development (ACTED)., 2014. Behind the Concrete Veil: Humanitarian Needs of Vulnerable, Crisis-Affected Refugee and Host Families in Urban and Peri-Urban Areas of Beirut and Mount Lebanon \{online\}. Paris. ACTED. Available at: http://reliefweb.int/report/lebanon/behind-concrete-veil-humanitarian-needs-vulnerable-crisisaffected-refugee-and-host \{Accessed 10 July 2015\}

Al-Masri, M. 2015. Between Local Patronage Relationships and Securitization: The Conflict Context in the Bekka Region \{online\}. Beirut. Lebanon Support. Beirut. UNDP (Lebanon). Available at:

http://www.lb.undp.org/content/lebanon/en/home/library/crisis_prevention_and_recovery/undpconflict-analysis-report/ \{Accessed 07 July 2015\}

Beirut Research and Innovation Centre., 2013. Survey on the Livelihoods of Syrian Refugees in Lebanon \{online\}. Beirut. Beirut Research and Innovation Centre. Available at: https://www.oxfam.org/sites/www.oxfam.org/files/rr-bric-livelihoods-syrian-refugees-lebanon211113-en.pdf \{Accessed 06 July 2015\}

Bujones, A.K, Jaskiewicz, K, Linakis, L, McGirr, M., 2013. A Framework for Analysing Resilience in Fragile and Conflict-Affected Situations \{online\} Washington DC. Columbia University School of Public and International Affairs (SPIA). Available at: http://pdf.usaid.gov/pdf_docs/pbaab059.pdf \{Accessed July 6, 2015\}

Chaaban, J, Ghattas, H, Habib, R, Hanafi, S, Sahyoun, N, Salti, N, Seyfert, K, Naamani, N., 2010. Socio-Economic Survey of Palestinian Refugees in Lebanon \{online\}. Beirut. American University of Beirut. Available at: http://www.unrwa.org/userfiles/2011012074253.pdf \{Accessed 04 July 2015$\}$

Danish Refugee Council (DRC)., 2012. DRC Livelihood Assessment - Bekka - May 2012 \{online\} KØbenhavn. Danish Refugee Council. Available at: http://drc.dk/home/ \{Accessed July $5,2015\}$

Hastie, R, Nunn, R and Martlew, N., 2010. Evaluation of Global Protection: Part One (Executive Summary). Oxford. Oxfam GB (Great Britain)

Hastie, R, Nunn, R and Martlew, N., 2010. Evaluation of Global Protection: Part Two (Executive Summary). Oxford. Oxfam GB (Great Britain)

Integrity Research and Consultancy., 2014. Conflict Sensitivity Institutional Capacity Assessment: Primary Healthcare Sector in Lebanon: Assessment Report, Conflict Sensitivity Checklist and Indicators for Community Perceptions \{online\}. London. International Alert. Available at: http://www.international-alert.org/resources/publications/conflict-sensitivityassessment \{Accessed 07 July, 2015\}

International Labour Organisation (ILO)., 2014. Assessment of the Impact of Syrian Refugees in Lebanon and Their Employment Profile \{online\} Beirut. International Labour Organisation, Regional Office for the Arab States. Available at: http://www.ilo.org/wcmsp5/groups/public/--arabstates/---ro-beirut/documents/publication/wcms_240134.pdf \{Accessed July 5, 2015\} 
Norwegian Refugee Council (NRC)., 2014. Needs Assessments in the Palestinian Gatherings of Lebanon \{online\} Oslo. NRC. Available at: http://reliefweb.int/report/lebanon/needs-assessmentpalestinian-gatherings-lebanon-housing-water-and-sanitation \{Accessed July 5, 2015\}

Norwegian Refugee Council (NRC)., 2014 (2). Increasing Security of Tenure Through Relationship Building and Written Lease Agreements: An Assessment of NRC's Housing, Land and Property Rights Pilot Project in Lebanon \{online\} Oslo. NRC. Available at: http://www.nrc.no/arch/_img/9195238.pdf \{Accessed July 5, 2015\}

Norwegian Refugee Council (NRC)., 2014 (3). The Consequences of Limited Legal Status for Syrian Refugees in Lebanon: NRC Field Assessment \{online\} Oslo. Norwegian Refugee Council. Available at: http://www.nrc.no/arch/_img/9167279.pdf \{Accessed July 5, 2015\}

Office for the Coordination of Humanitarian Affairs (OCHA) and REACH., (August) 2014. Preliminary Analysis for Sector Planning \{online\}. New York. OCHA. Geneva. REACH. Available at:

Office for the Coordination of Humanitarian Affairs (OCHA) and REACH., 2014. Informing Targeted Host Community Programming in Lebanon: Secondary Data Review \{online\}. New York. OCHA. Geneva. REACH. Available at: http://www. alnap.org/resource/19473 \{Accessed July 7,2015$\}$

Serrato, B.C., 2014. Refugee Perceptions Study: Za'atari Camp and Host Communities in Syria \{online\}. Oxford. Oxfam International. Available at: http://policypractice.oxfam.org.uk/publications/refugee-perceptions-study-zaatari-camp-and-hostcommunities-in-jordan-317655 \{Accessed 05 July 2015\}

Syria Needs Analysis Project (SNAP)., 2013. Legal Status of Individuals Fleeing Syria \{online\}. Geneva. Assessment Capabilities Project (ACAPS). Available at:

http://reliefweb.int/sites/reliefweb.int/files/resources/legal_status_of_individuals_fleeing_syria.pd f \{Accessed 05 July 2015\}

Syria Needs Analysis Project (SNAP)., 2014. Scenarios: Where Is Lebanon Heading Now? \{online\}. Geneva. Assessment Capabilities Project (ACAPS). Available at:

http://reliefweb.int/sites/reliefweb.int/files/resources/s-140822-scenarios-lebanon.pdf \{Accessed 05 July 2015\}

Tana., 2014. The Syrian displacement crisis and a Regional Development and Protection Programme: Mapping and meta-analysis of existing studies of costs, impacts and protection \{online\} Copenhagen. Ministry of Foreign Affairs/Tana. Available at:

http://www.rsc.ox.ac.uk/publications/the-syrian-displacement-crisis-and-a-regional-developmentand-protection-programme-mapping-and-meta-analysis-of-existing-studies-of-costs-impactsand-protection \{Accessed July 6, 2015\}

Tatwir Association for Strategic Studies and Human Development., 2015. Needs Assessments of Palestinian Refugees from Syria: Survey Results \{booklet\}. Beirut. Tatwir Association for Strategic Studies and Human Development.

United Nations Refugee Agency (UNHCR)., 2006. An Exploration of the Livelihood Strategies of Congolese Refugees. Geneva. UNHCR. Available at: http://www.unhcr.org/43fedead2.pdf \{Accessed 06 July\}

United Nations Refugee Agency (UNHCR)., 2014. Living in the Shadows: Jordan Home Visits Report 2014 \{online\}. Geneva. UNHCR. Available at: http://www.unhcr.org/54b685079.pdf \{Accessed July 5, 2015\}

United Nations Relief and Works Agency (UNRWA)., 2014. Needs Assessment for Palestinian Refugees from Syria \{online\}. East Jerusalem. UNRWA. Available at: 
http://reliefweb.int/report/lebanon/needs-assessment-palestine-refugees-syria \{Accessed July 5 , $2015\}$

WFP, UNHCR and UNICEF., 2013. Vulnerability Assessment of Syrian Refugees in Lebanon: 2013 Report \{online\}. Rome. WFP. Available at:

https://data.unhcr.org/syrianrefugees/download.php?id=3853 \{Accessed July 6, 2015\}

WFP, UNHCR and UNICEF., 2014. 2014 Vulnerability Assessment of Syrian Refugees in Lebanon \{online\}. Geneva: UNHCR. Available at: http://reliefweb.int/report/lebanon/syrianrefugee-response-vulnerability-assessment-syrian-refugees-lebanon-8-aug-2014 \{Accessed 04 July 2015$\}$

World Bank., 2013. Lebanon: Economic and Social Impact Assessment of the Syrian Conflict \{online\}. Washington DC. World Bank. Available at: http://documents.worldbank.org/curated/en/2013/09/18292074/lebanon-economic-socialimpact-assessment-syrian-conflict \{Accessed 7 July, 2015\}

\section{ONLINE NEWSPAPER ARTICLES}

Associated Press. 2015. Flow of Syrian Refugees to Lebanon Drops After Restrictions, The Daily Star (Lebanon) \{online\}, January 20. Available at:

http://www.dailystar.com.lb/News/Lebanon-News/2015/Jan-20/284715-flow-of-syrian-refugeesto-lebanon-drops-after-restrictions.ashx \{Accessed 5 July, 2015]

Kadi, S. 2015. Tight Lebanon Entry Rules Dissuade Would-Be Syria Refugees, The Daily Star (Lebanon) \{online\}, June 8. Available at: http://www.dailystar.com.lb/News/Lebanon-

News/2015/Mar-10/290206-tight-lebanon-entry-rules-dissuade-would-be-syria-refugees.ashx \{Accessed 7 July, 2015]

Kullab, S. 2015. Underfunded UNRWA to Run Out of Cash by October, The Daily Star (Lebanon) \{online\}, June 11. Available at: http://www.dailystar.com.lb/News/LebanonNews/2015/Jun-10/301351-underfunded-unrwa-to-run-out-of-cash-by-october.ashx \{Accessed 7 July, 2015]

Miliband, D. The World's Aid Programmes Are Heroic, But Inadequate Where It's Most Needed, The Guardian \{online\}, June 22. Available at:

http://www.theguardian.com/commentisfree/2015/jun/22/aid-programmes-human-catastrophefragile-states-cash [Accessed 6 July, 2015]

Shaheen, K. 2015. Life Goes From Bad to Worse for Syrians After Lebanon Tightens Border Controls, The Guardian \{online\}, March 12. Available at:

http://www.theguardian.com/world/2015/mar/12/syrians-lebanon-border-controls-un-refugee \{Accessed 6 July, 2015]

The Daily Star (Lebanon). 2015. Syrians Largest Refugee Group after Palestinians. The Daily Star (Lebanon) \{online\}. January 7. Available at: http://www.dailystar.com.lb/News/MiddleEast/2015/Jan-07/283233-syrians-largest-refugee-group-after-palestinians-un.ashx [Accessed 5 July, 2015\}

The Daily Star (Lebanon). 2015b. Two Lebanon Residents Killed Alongside ISIS in Lebanon The Daily Star (Lebanon) \{online\}, June 14. Available at: http://www.dailystar.com.Ib/News/Lebanon-News/2015/Jun-14/302012-two-lebanon-residentskilled-alongside-isis-in-syria.ashx \{Accessed 5 July, 2015] 
The Economist., 2013. Blackout. The Economist \{online\}, August 3. Available at: http://www.economist.com/news/middle-east-and-africa/21582570-power-cuts-are-symptomdeeper-malaise-blackout \{Accessed 10 July, 2015\}

Schwartzstein, P. 2015. Syrian Refugees in Lebanon Camp Reliant on 'Hell Water' that Reduces Water to Rust. The Guardian \{online]. May 26. Available at: http://www.theguardian.com/global-development/2015/may/26/syrian-refugees-lebanon-shatilacamp-hell-water \{Accessed 10 July, 2015\}

Zaatari, M. 2015. Clash Raises Fears in Ain al-Hilweh. The Daily Star (Lebanon) \{online\}. June 20. Available at: http://www.dailystar.com.Ib/News/Lebanon-News/2015/Jun-20/302972-clashraises-fears-in-ain-al-hilweh.ashx \{Accessed 10 July, 2015\}

\section{WEBSITE RESOURCES AND ONLINE ARTICLES}

Anderson, C., 2010. Presenting and Evaluating Qualitative Research, American Journal of Pharmaceutical Education, 74 (8). Available at: http:/www.ajpe.org/toc/ajpe/74/8 [Accessed 10 July, 2015\}

Central Intelligence Agency (CIA)., 2014. The World Factbook [online]. Available at: https:/www.cia.gov/library/publications/the-world-factbook/fields/2177.html \{Accessed 8 July, 2015]

Davis, R. E., Couper, M. P., Janz, N. K., Caldwell, C. H., \& Resnicow, K. (2010). Interviewer effects in public health surveys. Health Education Research, 25 (1), 14-26. Available at: http://her.oxfordjournals.org/content/25/1.toc \{Accessed 10 July, 2015\}

Lamba, N and Krahn, H., 2003. Social Capital and Refugee Resettlement: The Social Networks of Refugees in Canada. Journal of International Migration and Integration, 4 (3), 335-360. Available at: http://link.springer.com/journal/12134/4/3/page/1 \{Accessed 06 July 2015\}

Landau, L.B. and Duponchel, M., 2011. Laws, Policies or Social Position ? Capabilities and the Determinants of Effective Protection in Four African Cities, Journal of Refugee Studies, 24 (1), 1-22. Available at: http://jrs.oxfordjournals.org/ \{Accessed 06 July 2015\}

Romero, S.M., 2015. WFP experiences of vulnerability assessment of Syrian refugees in Lebanon. \{online\} Oxford. Field Exchange. Available at:

http://www.ennonline.net/fex/48/wfpexperiences \{Accessed 04 July 2015\}

Zetter, R and Ruande, H., 2014. Development and Protection Challenges of the Syrian Refugee Crisis. \{online\} Oxford. Forced Migration Review. Available at:

http://www.fmreview.org/syria/zetter-ruaudel \{Accessed 06 July 2015\}

\section{OXFAM STRATEGY DOCUMENTS}

Oxfam., 2014a. Lebanon Country Strategy 2014-2016. Oxford. Oxfam

Oxfam., 2014b. Syria Civil Society Strategy 2014-2016. Oxford. Oxfam

Oxfam., 2014c. Syria Country Strategy 2014-2016. Oxford. Oxfam

Oxfam., 2014d. Jordan Country Strategy 2014-2017. Oxford. Oxfam

Oxfam., 2014e. Oxfam Syria Crisis Response Strategy 2014-2017. Oxford. Oxfam 


\section{NGO AND INGO RESEARCH REPORTS/PAPERS}

Act for Human Rights (ALEF)., 2013. Two Years On: Syrian Refugees in Lebanon. Beirut. ALEF.

Act for Human Rights (ALEF)., 2014. Position Paper on Solutions to The Syrian Refugee Crisis in Lebanon. Beirut. ALEF

Agency for Technical Co-operation and Development (ACTED)., 2014. Behind the Concrete Veil \{online\}. Beirut. ACTED. Available at: http://www.acted.org/en/behind-concrete-veil \{Accessed 04 July 2015\}

Allegrozzi, I and Ford, E., 2013. Piecing Together the Jigsaw: Prospects for Improved Social Relations After the Armed Conflict in Northern Mali \{online\}. Oxford. Oxfam International. Available at: https://www.oxfam.org/en/research/piecing-together-jigsaw \{Accessed 06 July 2015\}

Christopherson, M, Thorleifsson, C.A. and Tiltnes, Å. A., 2013. Ambivalent Hostility: Coping Strategies and Local Responses to Syrian Refugees in Lebanon \{online\}. Oslo. Fafo Research Foundation. Available at: http://reliefweb.int/sites/reliefweb.int/files/resources/20338.pdf \{Accessed 04 July 2015\}

El-Masri, R, Harvey, C and Garwood, R., 2013. Shifting Sands: Changing Gender Roles Among Refugees in Lebanon \{online\} Beirut. Oxford. Oxfam International. Available at: http://policypractice.oxfam.org.uk/publications/shifting-sands-changing-gender-roles-among-refugees-inlebanon-300408 \{Accessed 05 July 2015\}

Handicap International and Helpage International,. 2014. Hidden Victims of the Syrian Crisis: Disabled, Injured and Older Refugees \{online\}. London. Handicap International and Helpage International. Available at: http://www.helpage.org/newsroom/latest-news/hidden-victims-newresearch-on-older-disabled-and-injured-syrian-refugees/ \{Accessed 05 July 2015\}

Harb, C and Saab, R., 2014. Social Cohesion and Intergroup Relations: Syrian Refugees and Lebanese Nationals in the Bekka and Akkar \{online\}. London. Save the Children. Available at: http://reliefweb.int/report/lebanon/social-cohesion-and-intergroup-relations-syrian-refugees-andlebanese-nationals-bekaa \{Accessed 05 July 2015\}

International Poverty Centre., 2008. Poverty, Growth and Income Distribution in Lebanon \{online\}. New York. United Nations Development Programme (UNDP). Available at: http://www.ipc-undp.org/pub/IPCCountryStudy13.pdf \{Accessed 13 June 2015\}

International Rescue Committee (IRC)., 2014. Are We Listening? Acting On Our Commitments to Women and Girls Affected by the Syria Conflict \{online\} New York. IRC. Available at: http://www.rescue.org/sites/default/files/page_wrappers/assets/syria/pdf/IRC_WomenlnSyria_R eport_WEB.pdf $\{$ Accessed 05 July 2015\}

Mercy Corps., 2013. Things Fall Apart: Political, Social and Economic Instability in Lebanon \{online\} Portland, Oregon. Mercy Corps. Available at: http://www.mercycorps.org.uk/researchresources/political-economic-and-social-instability-lebanon \{Accessed 07 July, 2015\}

Mercy Corps., 2014. Advancing Adolescence: Getting Syrian Refugee and Host-Community Adolescents Back On Track \{online\}Portland, Oregon. Mercy Corps. Available at: https://data.unhcr.org/syrianrefugees/download.php?id=5366 \{Accessed 06 July 2015\} 
Search for Common Ground., November 2013-January 2014. Dialogue and Local Response Mechanisms to Conflict Between Host Communities and Syrian Refugees in Lebanon \{online\} Beirut. Searching for Common Ground. Available at: http://www.alnap.org/resource/12640 \{Accessed 07 July 2015\}

Slim, H and Bonwick, A., 2005. Protection: An ALNAP Guide for Humanitarian Agencies \{online\} London. Overseas Development Institute (ALNAP). Available at http://www.alnap.org/resource/5263 \{Accessed 07 July 2015\}

United Nations Children's Fund (UNICEF)., 2014. Under Siege: The Devastating Impact on Children of Three Years of Conflict in Syria \{online\}. New York. UNICEF. Available at: http://childrenofsyria.info/2014/03/11/under-siege-the-devastating-impact-on-children-of-threeyears-of-conflict-in-syria/ \{Accessed 05 July 2015\}

United Nations Refugee Agency (UNHCR) and United Nations Human Settlements Programme (UN-Habitat)., 2014 (2). Housing, Land and Property Issues in Lebanon: Implications of the Syrian Refugee Crisis. Beirut. UNHCR. Beirut. UN-Habitat

United Nations Relief and Works Agency (UNRWA)., 2014b. 2014 Syria Crisis Response: Annual Report \{online\}. Amman. UNRWA. Available at: http://www.unrwa.org/resources/reports/syria-2014-crisis-response-report \{Accessed 07 July 2007\}

World Vision International., 2014. Stand With Me: Our Uncertain Future \{online\}. Uxbridge (UK). World Vision International. Available at: http://www.alnap.org/resource/10857 \{Accessed 06 July 2015\}

\section{MISCELLANEOUS DOCUMENTS}

General Directorate of General Security (GSO)., 2015. GSO Circular Decision. \{Government Guidelines\}. Beirut. Government of Lebanon

General Directorate of General Security (GSO)., 2015. GSO New Rules \{Updated Government Guidelines\}. Beirut. Government of Lebanon

International Committee for the Red Cross (ICRC)., 2013. Professional Standards for Protection Work: Carried Out By Humanitarian and Human Rights Actors in Armed Conflict And Other Situations of Violence \{Guidance Document\}. Geneva: UNHCR. Available at: https://www.icrc.org/eng/resources/documents/publication/p0999.htm

Multi-Sectoral Needs Assessment. 2014. Social Cohesion \{Report Chapter\}

Norwegian Refugee Council (NRC) and International Rescue Committee (IRC)., 2014. Update on Regularisation - for Basic Information at Awareness Sessions \{Update Document\}. Oslo. NRC. New York. IRC

Norwegian Refugee Council (NRC)., 2015. Legal Status of Refugees from SyriaConsequences of Recent Changes: Case Studies \{Guidance Document\}. Oslo. NRC

Norwegian Refugee Council (NRC)., 2015b. Legal Status of Refugees from SyriaConsequences of Recent Changes \{Guidance Document\}. Oslo. NRC

Oxfam GB. (no date) Putting Protection into Practice \{Policy Overview document\}. Oxford. Oxfam GB 
United Nations., 1989. Convention on the Rights of the Child \{UN Convention\}. Available at: http://www.ohchr.org/en/professionalinterest/pages/crc.aspx \{Accessed 10 July 2015]

United Nations Development Programme (UNDP) and Mercy Corps., 2015. Stabilisation and Resilience in Protracted, Politically-Induced Emergencies: A Case Study Exploration of Lebanon \{Case Study Report\} New York. UNDP. Portland, Oregon. Mercy Corps. Available at: http://www.mercycorps.org.uk/research-resources/stabilization-and-resilience-protractedpolitically-induced-emergencies-case $\{$ Accessed July 5, 2015\}

United Nations Refugee Agency (UNHCR)., (no date). Information for Dafi Students: Residence Permits in Lebanon \{Guidance Notes\}. Beirut. UNHCR

United Nations Refugee Agency (UNHCR)., 2011. Promoting Livelihoods and Self-Reliance: Operational Guidance on Refugee Protection and Solutions in Urban Areas. Geneva. UNHCR. Available at:

http://www.unhcr.org.uk/fileadmin/user_upload/images/news_images/October2011_news/Prom otingLivelihoodsandSelfReliance_3.pdf \{Accessed 07 July, 2015\}

United Nations Refugee Agency (UNHCR)., 2015a. New Procedures for Entering Lebanon \{Guidance Notes\}. Beirut. UNHCR

United Nations Refugee Agency (UNHCR)., 2015b. Admission and Residency: Syrians in Lebanon \{Information Sheet\}. Beirut. UNHCR

United Nations Refugee Agency (UNHCR)., 2015c. Q and A Related to 'New Entry \& Renewal Procedures for Syrians in Lebanon' \{Information Sheet\}. Beirut. UNHCR

United Nations Refugee Agency (UNHCR)., 2015d. Q and A for Refugees Related to 'Back to School' \{lnformation Sheet\}. Beirut. UNHCR

United Nations Refugee Agency (UNHCR)., 2015e. Registration Trends for Syrians in Lebanon \{Statistical Information Sheet\}. Beirut. UNHCR

United Nations Relief and Works Agency (UNRWA)., 2014c. PRS Statistics \{Statistical Overview\} Beirut. UNRWA, Department of Relief and Social Services (Lebanon Field Office)

United Nations Relief and Works Agency (UNRWA)., 2015. Lebanon: Lack of Funds Forces UNRWA to Suspend Cash Assistance for Palestine Refugees from Syria in Lebanon \{press release\}. 22 May 2015.

Wellington, J and Szczerbinski, M (2007) Research Methods for the Social Sciences; Continuum International Publishing, London and New York

\section{POLICY BRIEFINGS/POLICY UPDATES/BACKGROUND PAPERS}

Baudot, C., 2014. The Right Move? Ensuring Durable Relocation After Typhoon Haiyan \{online\} Oxford. Oxfam Great Britain. Available at: http://policy-

practice.oxfam.org.uk/publications?pscid=ps_ggl_GR_OXInternal_PolicyandPractice\&gclid=CL TXgri5xMYCFeHLtAodaOllgQ \{Accessed 05 July 2015\}

Christopherson, M and Thorleifsson, C., 2015. Lebanese Contradictory Responses to Syrian Refugees Include Stress, Hospitality, Resentment \{online\} Beirut. Issam Fares Institute for Public Policy and International Affairs. Oslo. Fafo Research Foundation. Available at: 
https://www.aub.edu.Ib/ifi/Documents/policy_memo/20130705ifi_memo_Fafo_IFI_Policy_brief_ Syrians_in_Lebanon.pdf \{Accessed 04 July 2015\}

Dinçer, O.B, Federici, V, Ferris, E, Karaca, S, Kirişci, K and Çarmikh, E.Ö., 2013. Turkey and Syrian Refugees: The Limits of Hospitality \{online\} Washington D.C. Brookings Institute. Tandoğan-Ankara. International Strategic Research Organisation (USAK). Available at: http://www.brookings.edu/research/reports/2013/11/14-syria-turkey-refugees-ferris-kiriscifederici \{Accessed 05 July 2015\}

Jaspars, S and O'Callaghan, S., 2010. Challenging Choices: Protection and Livelihoods in Conflict. London. Humanitarian Policy Group (HPG). Available at:

http://www.odi.org/sites/odi.org.uk/files/odi-assets/publications-opinion-files/6008.pdf \{Accessed 07 July 2015\}

United Nations Refugee Agency (UNHCR)., 2014. UNHCR Lebanon: Monthly Updates: December 2014. Beirut: UNHCR Lebanon. Available at: https://data.unhcr.org/syrianrefugees/download.php?id=8154 \{Accessed 06 July 2015\}

United Nations Refugee Agency (UNHCR)., 2014. Syrian Refugee Response: Interagency Update on Statelessness. Beirut. UNHCR Lebanon.

United Nations Relief and Works Agency (UNRWA) (2)., (November-December) 2014d. UNRWA Response and Services to Palestine Refugees from Syria (PRS) in Lebanon: Monthly Briefing. Beirut. UNRWA. Available at:

http://www.unrwa.org/sites/default/files/prs_update_issue_41_1_nov_31_dec_2014.pdf \{Accessed 07 July 2015\}

United Nations Relief and Works Agency (UNRWA)., (January-February) 2015a. UNRWA Response and Services to Palestine Refugees from Syria (PRS) in Lebanon: Monthly Briefing. Beirut. UNRWA. Available at:

http://www.unrwa.org/sites/default/files/prs_update_issue_42_01_jan_28_feb.pdf \{Accessed 10 July 2015\}

United Nations Relief and Works Agency (UNRWA)., (March-April) 2015b. UNRWA Response and Services to PRS in Lebanon: Bimonthly Briefing. Beirut: UNRWA. Available at:

http://reliefweb.int/report/lebanon/unrwa-response-and-services-palestine-refugees-syria-prslebanon-march-april-2015 \{Accessed 07 July 2015\}

Wannis, H., 2014. Security Threat Perceptions in Lebanon \{online\}. London. International Alert. Available at: http://www.international-alert.org/resources/publications/security-threatperceptions-lebanon $\{$ Accessed 07 July 2015\}

\section{UNPUBLISHED DOCUMENTS/COMMUNICATIONS}

International Rescue Committee Lebanon., 2014. Protection Working Group: 2014 Protection Trends \{Powerpoint Presentation\}. New York. IRC

International Rescue Committee (IRC)., 2014. Protection Monitoring Data Entry Sheet \{Data Entry Sheet\}. New York. IRC

International Rescue Committee (IRC)., 2015. IRC Protection Monitoring Form: Community Level Assessment \{Assessment/Monitoring Form\}. New York. IRC

International Rescue Committee (IRC)., 2015. Guidance Note on Community Level Protection Monitoring Form \{Monitoring Form\}. New York. IRC 
International Rescue Committee (IRC)., 2015. Protection Monitoring: Questionnaire - Group Interview \{General Questionnaire\}. New York. IRC

Lebanon Humanitarian INGO Forum., 2014.Unregistered Syrian Refugees in Lebanon \{background paper - pre-final draft\}. Beirut. INGO Forum.

Norwegian Refugee Council (NRC). 2014., The Consequences of Limited Legal Representation for Syrian Refugees in Lebanon \{Powerpoint Presentation\} Oslo. NRC

Oxfam., 2014f. Lebanon: An Increasingly Hostile Environment for Refugees \{confidential background note\}. Oxford. Oxfam

Oxfam., 2015. Briefing on Entry Regulations in Lebanon \{confidential briefing document\}. Oxford. Oxfam

United Nations Refugee Agency (UNHCR)., 2015. Confidential Briefing on Changes in UNHCR Registration Policy for Refugees in Lebanon \{briefing document\} Geneva. UNHCR

United Nations Relief and Works Agency (UNRWA)., 2015c. PRS Presentation \{Powerpoint Presentation\} East Jerusalem. UNRWA 


\section{APPENDIX - REGIONAL PROFILES}

These short regional profiles are designed to trace the arc of particular trends in each region focused upon in the study, as well as outline the overall situation in broad lines for each region. The profiles provide a quick reference that can aid for comparison between regions, and are best read in conjunction with the executive summary so as to be able to cross-reference details on the challenges, coping strategies and protection concerns. The five regions are: Beirut, Tripoli, the Bekaa (central and north), the South (around Saida) and Akkar in the north.

\section{BEIRUT}

\section{Main characteristics}

In Beirut, the study focused on the southern suburbs primarily around Sabra and Chatilla, speaking with a total of 37 interviewees (see table below). These neighbourhoods have absorbed a large number of refugees overall, and are characterized by significant urban poverty and overcrowding. While PRL and PRS are the largest population groups, there are also many Syrian refugees along with Lebanese host community members.

\begin{tabular}{|c|c|c|c|c|c|}
\hline \multicolumn{5}{|c|}{ Region: Beirut } \\
\hline Category of respondent & Male over $\mathbf{3 0}$ & Male 30 and under & Female over 30 & Female 30 and under & Total \\
\hline Syrian Refugees & 3 & 2 & 2 & 1 & 8 \\
\hline PRS & 4 & 1 & 2 & 2 & 9 \\
\hline Lebanese host communities & 2 & 6 & 3 & 2 & 11 \\
\hline PRL host communities & 1 & 1 & 5 & $\mathbf{5}$ & 9 \\
\hline Totals & $\mathbf{1 0}$ & $\mathbf{1 0}$ & $\mathbf{1 2}$ & $\mathbf{3 7}$ \\
\hline
\end{tabular}

\section{Main challenges, coping strategies and protection concerns}

The refugees in the Beirut area face strong employment challenges and despite the relatively more dynamic employment market in terms of the opportunities available, there is also more competition. Coping strategies such as child labour give rise to protection concerns, as do abusive employment situations. Shelter is relatively expensive compared with other study regions and also often of low quality, characterized by severe overcrowding and concerns about mould, poor air circulation and lack of green space. Problematic relationships with landlords are found in Beirut, though no more or less than in other regions. The legal status challenges of refugees are similar to other areas and mean that refugees move around very little and are constantly on the alert for raids by security forces. The living conditions contribute to generalized tensions in the street and also to health concerns that can however often be addressed without travel outside the area.

The influx of refugees has impacted upon host communities in terms of greater competition for jobs and lower salaries paid as well as increased overcrowding and relatively greater tensions in the street, which strongly contribute to the generalised sense of frustration with the situation. Overall however, the coping strategies adopted in response to these circumstances do not appear to us to present major protection concerns for the host communities.

\section{TRIPOLI}

\section{Main characteristics}

In the Tripoli area, the study focused on Tabbaneh neighbourhood as well as on the Palestinian refugee camp of Nahr al-Bared, speaking with a total of 40 interviewees (see table below).

Tabbaneh is very poor and saw significant security concerns, unrest and fighting until the recent 
move into the neighbourhood by the Lebanese army; Nahr al-Bared is also very poor and has only been partially rebuilt and repopulated following the 2007 fighting in the camp between militants and the Lebanese army.

\begin{tabular}{|c|c|c|c|c|c|}
\hline \multicolumn{7}{|c|}{ Region: Tripoli (including Nahr al Bared) } \\
\hline Category of respondent & Male over 30 & Male 30 and under & Female over 30 & Female 30 and under & Total \\
\hline Syrian Refugees & 5 & 4 & 3 & 4 & 16 \\
\hline PRS & 2 & 3 & 2 & 4 & 11 \\
\hline Lebanese host communities & 4 & 1 & 1 & 2 & 8 \\
\hline PRL host communities & 1 & 1 & $\mathbf{7}$ & $\mathbf{1 2}$ & 5 \\
\hline Totals & $\mathbf{1 2}$ & $\mathbf{9}$ & & $\mathbf{4 0}$ \\
\hline
\end{tabular}

\section{Main challenges, coping strategies and protection concerns:}

These neighbourhoods have absorbed a large number of refugees overall, and are characterised by quite severe urban poverty. Even more so than Beirut, there are significant employment challenges, with child labour and generally abusive and exploitative employment situations widespread in Tabbaneh. In Nahr al-Bared, there is very little work for refugees from Syria. Overcrowding and low quality of housing is an issue in Tabbaneh, though overcrowding is slightly different in Nahr al-Bared in that there is more space between buildings (due to the number of buildings that have not been rebuilt since the 2007 conflict) even if the actual living spaces of refugees are small and overcrowded. In general the price of the housing stock is lower than in Beirut; as in Beirut, problematic landlord relationships are an issue. The legal status situation is roughly comparable to Beirut, with refugees being careful about their movements and worried about raids. While the general security situation is better than it was in Tabbaneh - due to the army's presence - there is still a sense of insecurity in the streets; this is roughly similar in Nahr al-Bared, which is a demilitarised camp though is rough and refugees from Syria often feel targeted. Health concerns and education issues are relatively similar to Beirut.

Host communities in this region were already experiencing very difficult living situations prior to the outbreak of the Syria crisis, and this has only gotten worse with the arrival of so many people: finding jobs is harder, pay has decreased, and there is tension in the streets between refugees and host community members. Similar to Beirut, the coping strategies adopted in response to these circumstances do not appear to us to present major protection concerns for the host communities.

\section{BEKAA}

\section{Main characteristics}

In the Bekaa, the study focused on the central and northern areas, including the Palestinian refugee camp of Jaleel on the outskirts of Baalbek, speaking with a total of 48 interviewees (see table below). The Bekaa is in general a quite poor, rural area with ITS as well as towns and small cities. It is on the frontline of the fighting in Syria (at present taking place near Arsal), and has an overall tense security situation with control exerted by Hizballah or by the Lebanese army depending on the area. 


\begin{tabular}{|c|c|c|c|c|c|}
\hline \multicolumn{5}{|c|}{ Region: Bekaa } \\
\hline Category of respondent & Male over $\mathbf{3 0}$ & Male 30 and under & Female over 30 & Female 30 and under & Total \\
\hline Syrian Refugees & 5 & 3 & 5 & 5 & 18 \\
\hline PRS & 2 & 1 & 1 & 3 & 7 \\
\hline Lebanese host communities & 7 & 1 & 2 & 1 & 12 \\
\hline PRL host communities & 2 & 2 & 6 & 11 & 11 \\
\hline Totals & $\mathbf{1 6}$ & $\mathbf{7}$ & $\mathbf{1 4}$ & $\mathbf{1 1}$ & $\mathbf{4 8}$ \\
\hline
\end{tabular}

\section{Main challenges, coping strategies and protection concerns}

The employment situation for refugees living in ITS is very poor, with coping strategies involving having children and women work on a greater scale than in other regions. In the towns and villages the situation is slightly better, with these coping strategies slightly less prevalent though poor employment situations still abound, while in Jaleel there is very little work for refugees from Syria. Rural poverty involves less overcrowding and lower rent prices - though overcrowding is an issue in Jaleel - but generally low quality of housing and as elsewhere, challenging landlord relationships. The legal status challenges of refugees mean that they limit their movements; there is also greater direct control of refugees compared with in Beirut and Tripoli, by Hizballah and by groups of young men in areas associated with the group. Refugees still experience significant insecurity due to this control, though this is less the case for those refugees that are in Jaleel camp. Addressing health issues requires more travel as does accessing education compared to in the cities.

Host communities are affected in similar ways to host communities in other regions, with employment challenges and tension with refugees. While in general the coping strategies adopted do not appear to us to present major protection concerns for the host communities, there is an important possibility for confrontation as a result of the direct control imposed on refugees and generally higher tensions due to the proximity of the fighting in Syria.

\section{THE SOUTH (AROUND SAIDA)}

\section{Main characteristics}

In the Saida area, the study focused on the downtown as well as on the Palestinian refugee camp of Ayn al-Helweh, speaking with a total of 48 interviewees (see table below). Saida is an urban area that is relatively better off than Beirut and Tripoli, while Ayn al-Helweh is a very poor camp with significant security concerns and overcrowding.

\begin{tabular}{|c|c|c|c|c|c|}
\hline \multicolumn{5}{|c|}{ Region: South } \\
\hline Category of respondent & Male over $\mathbf{3 0}$ & Male 30 and under & Female over 30 & Female 30 and under & Total \\
\hline Syrian Refugees & 3 & 2 & 1 & 3 & 9 \\
\hline PRS & 6 & 2 & 7 & 3 & 1 \\
\hline Lebanese host communities & 2 & 4 & 4 & 1 & 11 \\
\hline PRL host communities & 2 & 6 & 1 & $\mathbf{8}$ & 10 \\
\hline Totals & $\mathbf{1 3}$ & $\mathbf{1 4}$ & $\mathbf{1 3}$ & $\mathbf{4 8}$ \\
\hline
\end{tabular}

\section{Main challenges, coping strategies and protection concerns}

While there are significant employment concerns in Saida, the employment situation is in general a bit better than in Beirut and Tripoli. That said, there are still problematic coping strategies including child labour and all too often abusive or exploitative employment situations. There is very little work for refugees from Syria in Ayn al-Helweh. The shelter situation is slightly better than in the other cities in terms of quality and cost though very poor in the overcrowded Palestinian refugee camp. As elsewhere, the landlord relationship remains a crucial one and a potential source of protection concerns. The legal status situation for the refugees is the same 
as elsewhere, and refugees respond by limiting their movement and worry about raids. The overall sense of security seems slightly better than in other cities, with the exception of Ayn alHelweh which is perhaps the least secure of the areas examined in the study. Health and education concerns are relatively similar to the other two cities.

Host communities in this region are experiencing the impact of the arrival of so many refugees in a similar way to those in other regions: greater competition for jobs and lower wages, rising rents and a general sense of overcrowding and greater tension. The last two factors are particularly pronounced in Ayn al-Helweh. The coping strategies adopted do not in general seem to present major protection concerns with the notable exception of joining of militias in Ayn al-Helweh by some refugees.

\section{AKKAR}

\section{Main characteristics}

In Akkar, the study focused on towns and villages as well as several ITS throughout the region, to capture the range of experiences. A total of 36 interviewees were engaged with. There is only a very small Palestinian presence in Akkar, thus the study did not speak with PRS or PRL. In general, Akkar is the poorest region of Lebanon, quite rural, relatively ignored by the central government, and also directly on the border with Syria. There are moreover many cross-border familial connections, friendships and work relationships, especially in the Wadi Khaled area.

\begin{tabular}{|c|c|c|c|c|c|}
\hline \multicolumn{5}{|c|}{ Region: North (Akkar) } \\
\hline Category of respondent & Male over $\mathbf{3 0}$ & Male 30 and under & Female over 30 & Female 30 and under & Total \\
\hline Syrian Refugees & 5 & 4 & 4 & 8 & 21 \\
\hline PRS * & 0 & 0 & 0 & 0 & 0 \\
\hline Lebanese host communities $^{*}$ & 9 & 1 & 3 & 2 & 15 \\
\hline PRL host communities ${ }^{*}$ & 0 & 0 & 0 & 0 & 0 \\
\hline Totals & $\mathbf{1 4}$ & $\mathbf{5}$ & $\mathbf{7}$ & $\mathbf{1 0}$ & $\mathbf{3 6}$ \\
\hline
\end{tabular}

\section{Main challenges, coping strategies and protection concerns}

The employment situation and coping strategies in Akkar are similar to those found in the Bekaa - very poor in ITS with women and children working a lot, and a similar situation in towns and villages. Shelter and food situations are also similar to in the Bekaa, with less overcrowding than in the cities like Beirut and Tripoli and among the lowest rent prices in Lebanon though poor housing quality. While the legal status situation of refugees is the same as elsewhere, there is slightly less concern about raids and in general a slightly more relaxed attitude to enforcing the rules than in other regions. Insecurity is slightly lesser in Akkar than in other areas, though curfews are in place with overall control of refugees carried out more informally at the municipal level. As in the Bekaa, addressing health issues requires more travel as does accessing education compared to in the cities.

Host communities were already among the poorest in Lebanon before the arrival of the refugees, and this has only gotten worse as a result of the influx, exacerbated by the extent to which the region is ignored by the central government and relatively less engaged with by aid agencies. As in some other regions, the coping strategies adopted do not appear to us to present major protection concerns for the host communities. 
1 This section draws upon the Terms of Reference for the assignment, as well as on the project-related documents provided to the consultant

2 UNHCR, 'Registration Trends for Syrians in Lebanon', 26 March 2015.

'UNRWA response and services to Palestine refugees from Syria (PRS) in Lebanon', monthly briefing, 01 January - 28 February 2015, issue 42.

3 http://www.dailystar.com.Ib/News/Lebanon-News/2015/Jan-20/284715-flow-of-syrian-refugees-tolebanon-drops-after-restrictions.ashx

4 http://www.dailystar.com.lb/News/Middle-East/2015/Jan-07/283233-syrians-largest-refugee-group-afterpalestinians-un.ashx

5 UNHCR, 'Registration Trends for Syrians in Lebanon', 26 March 2015.

62014 Vulnerability Assessment of Syrian Refugees in Lebanon.

7 'Poverty, Growth and Income Distribution in Lebanon', International Poverty Centre Country Study, Number 13, January 2008. Available at: http://www.ipc-undp.org/pub/lPCCountryStudy13.pdf (last accessed June 13, 2015).

8 Indeed, this intertwining of the two results in a need to consider them together so as to better understand each and also to build linkages between them as a means to achieve more positive outcomes in addressing them.

For further discussion of this issue, see for example: 'Challenging Choices: Protection and Livelihoods in Conflict', by Susanne Jaspars and Sorcha O'Callaghan, Humanitarian Policy Group, Overseas Development Institute, May 2010.

9 http://policy-practice.oxfam.org.uk/our-work/conflict-disasters/protection

10 The framework focuses on three main threats, which become protection threats when they take place in a widespread and systematic manner: (a) Violence - including deliberate killing, wounding, torture, cruel and inhuman and degrading treatment, sexual violence including rape, and the threat of any of the above; (b) Coercion - including forced prostitution, sexual slavery, sexual exploitation, forced or compulsory labour, forced displacement or return, forced recruitment into armed forces, and being forced to commit acts of violence against others; (c) Deliberate deprivation - including deliberately destroying civilian objects such as homes, wells, crops and clinics; preventing access to land and jobs; preventing the delivery of relief supplies; deliberate discrimination in getting jobs, schooling, land, services, etc.; and demanding illegal 'taxes' or tolls. According to Oxfam's Protection Framework, people become vulnerable as a result of: crisis situations, where people are vulnerable to threats for a wide variety of reasons; crisis environments - often characterised by a lack of law and order, a proliferation of small arms, and a breakdown of the social structures and behaviours that protect the most vulnerable people; poverty - whereby people are more vulnerable as they have fewer resources to draw upon to sustain and protect themselves and their families. Certain events can also heighten vulnerability.' When people are vulnerable and face the threats outlined above, they are at risk. The longer or more frequently they encounter such threats, the higher the level of risk.

11 Wellington, J. and Szczerbinski, M.; (2007) Research Methods for the Social Sciences; Continuum International Publishing, London and New York; p. 20.

12 lbid. p. 81.

13 Anderson, C. (2010). Presenting and Evaluating Qualitative Research. American Journal of Pharmaceutical Education, 74(8), 141, p. 2

14 lbid. pp. 87-88.

15 CIA World Factbook (https://www.cia.gov/library/publications/the-world-factbook/fields/2177.html)

16 Some refugees seemed to become discouraged at the lack of opportunities and not actively seek work for a short period of time, though all were still interested and would pursue opportunities should they arise. This phenomenon was particularly noticeable among PRS and especially PRS in camp settings, as a result of the much lower level of employment opportunities there.

17 There are multiple ways that money is sent back and forth across the border: through Western Union; by paying a fee of approximately US $\$ 25$ to send the money through a Syrian-Lebanese travel agency (though actual money doesn't cross the border - rather, the agency will call a trusted person in the other country and say they have the money; that second person will then give money to the receiver); and by sending money with a taxi driver for a fee of approximately US $\$ 25$. There was no clear evidence that the method of transferring money has changed since tighter border controls were put into place.

18 'States Parties recognize the right of the child to be protected from economic exploitation and from performing any work that is likely to be hazardous or to interfere with the child's education, or to be harmful to the child's health or physical, mental, spiritual, moral or social development.' (http://www.ohchr.org/en/professionalinterest/pages/crc.aspx) 
19 'Assessment of the Impact of Syrian Refugees in Lebanon and their Employment Profile', International Labour Organization Regional Office for the Arab States, 2013, p. 8-14. See also: 'Behind the Concrete Veil: Humanitarian needs of vulnerable crisis-affected refugee and host families in urban and periurban areas of Beirut and Mount Lebanon', Acted, May 2014.

20 http://www.dailystar.com.lb/News/Lebanon-News/2015/Jun-10/301351-underfunded-unrwa-to-run-outof-cash-by-october.ashx

21 The issue of water quality is particularly a concern in Beirut. See: http://www.theguardian.com/globaldevelopment/2015/may/26/syrian-refugees-lebanon-shatila-camp-hell-water

22 'UNRWA Response and Services to Palestine Refugees From Syria (PRS) in Lebanon', Monthly Briefing, 01 January - 28 February 2015, issue 42.

23 'Legal Status of Refugees from Syria - Consequences of recent changes', Norwegian Refugee Council, March 2015.

24 http://www.dailystar.com.lb/News/Lebanon-News/2015/Jan-20/284715-flow-of-syrian-refugees-tolebanon-drops-after-restrictions.ashx

25 'Legal Status of Refugees from Syria - Consequences of recent changes', Norwegian Refugee Council, March 2015.

26 'UNRWA Response and Services to Palestine Refugees From Syria (PRS) in Lebanon', Monthly Briefing, 01 January - 28 February 2015, issue 42; 'UNRWA Response and Services to PRS in Lebanon', Bimonthly Briefing, March - April 2015, issue 43.

27 That is, Lebanese and PRL do not differentiate between PRS and Syrians, rather they are all seen as Syrian and treated accordingly.

28 While this phenomenon pre-existed the Syria crisis, the desperate circumstances of many Syrian refugees and their significantly greater numbers post-2011 would suggest that the prevalence of the phenomenon has increased.

29 For more on this issue, see: 'Needs Assessment for Refugees From Syria', UNRWA, March 2014.

30 A 2008 study by the International Poverty Centre found that about $28 \%$ of the Lebanese population is poor and some $8 \%$ is extremely poor. See: http://www.ipc-undp.org/pub/IPCCountryStudy13.pdf pg. 1. The PRL population clusters disproportionately in line with this group of Lebanese. See: 'SocioEconomic Survey of Palestinian Refugees in Lebanon', American University of Beirut, 2010.

$31 \mathrm{http}: / /$ www.ipc-undp.org/pub/IPCCountryStudy13.pdf pg. 4 of report.

32 'Socio-Economic Survey of Palestinian Refugees in Lebanon', American University of Beirut, 2010, p. xi-xii.

33 For more on this, see: http://www.theguardian.com/global-development/2015/may/26/syrian-refugeeslebanon-shatila-camp-hell-water

34 Lebanon already had a marked gap between supply and demand of electricity prior to the 2011 crisis, a situation that has only gotten worse with the number of new arrivals. For more on this, see: http://www.economist.com/news/middle-east-and-africa/21582570-power-cuts-are-symptom-deepermalaise-blackout

35 It is important to note that there was rarely any differentiation made between Syrians and PRS by either Lebanese or PRL - rather, they spoke of them all as 'Syrians'.

36 'Syrian' in this section refers to Syrians and to PRS, since the interviewees referred to them both as Syrian.

37 Conversely, some PRS spoke with sympathy about the conditions of the PRL relative to their own situation pre-2011 in Syria. 
This paper was written by Mónica Treviño and Robert Stewart from Merits Partnership and Oxfam. It is part of a series of reports written to inform public debate on development and humanitarian policy issues.

For further information on the issues raised in this paper please e-mail Valentina Bacchin at VBacchin@oxfam.org.uk or go to www.oxfam.org

(C) Oxfam International June 2016

This publication is copyright but the text may be used free of charge for the purposes of advocacy, campaigning, education, and research, provided that the source is acknowledged in full. The copyright holder requests that all such use be registered with them for impact assessment purposes. For copying in any other circumstances, or for re-use in other publications, or for translation or adaptation, permission must be secured and a fee may be charged. Email policyandpractice@oxfam.org.uk

The information in this publication is correct at the time of going to press.

Published by Oxfam GB for Oxfam International under ISBN 978-0-85598-753-4 in June 2016.

Oxfam GB, Oxfam House, John Smith Drive, Cowley, Oxford, OX4 2JY, UK.

\section{OXFAM}

Oxfam is an international confederation of 18 affiliates and 2 observer organizations networked together in more than 90 countries, as part of a global movement for change, to build a future free from the injustice of poverty. Please write to any of the agencies for further information, or visit www.oxfam.org

Oxfam America (www.oxfamamerica.org)

Oxfam Australia (www.oxfam.org.au)

Oxfam-in-Belgium (www.oxfamsol.be)

Oxfam Canada (www.oxfam.ca)

Oxfam France (www.oxfamfrance.org)

Oxfam Germany (www.oxfam.de)

Oxfam GB (www.oxfam.org.uk)

Oxfam Hong Kong (www.oxfam.org.hk)

IBIS (Denmark) (www.ibis-global.org)

Oxfam India (www.oxfamindia.org)

Oxfam Intermón (Spain) (www.intermonoxfam.org)

Oxfam Ireland (www.oxfamireland.org)

Oxfam Italy (www.oxfamitalia.org)
Oxfam Japan (www.oxfam.jp)

Oxfam Mexico (www.oxfammexico.org)

Oxfam New Zealand (www.oxfam.org.nz)

Oxfam Novib (Netherlands) (www.oxfamnovib.nl)

Oxfam Québec (www.oxfam.qc.ca)

Observers:

Oxfam Brasil (www.oxfam.org.br)

Oxfam South Africa
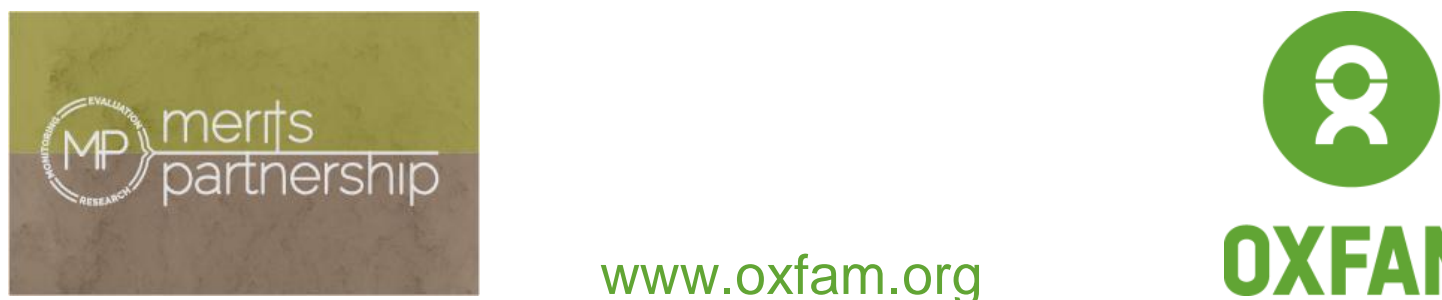